\title{
Persistence of foodborne pathogens and their control in primary and secondary food production chains
}

Larsen, Marianne Halberg; Dalmasso, Marion; Ingmer, Hanne; Langsrud, Solveig;

Malakauskas, Mindaugas; Mader, Anneluise; Møretrø, Trond; Mozina, Sonja Smole; Rychli, Kathrin; Wagner, Martin; Wallace, R. John; Zentek, Jurgen; Jordan, Kieran

\section{Published in:}

Food Control

DOI:

10.1016/j.foodcont.2014.03.039

Publication date:

2014

\section{Document version}

Early version, also known as pre-print

\section{Citation for published version (APA):}

Larsen, M. H., Dalmasso, M., Ingmer, H., Langsrud, S., Malakauskas, M., Mader, A., Møretrø, T., Mozina, S. S., Rychli, K., Wagner, M., Wallace, R. J., Zentek, J., \& Jordan, K. (2014). Persistence of foodborne pathogens and their control in primary and secondary food production chains. Food Control, 44, 92-109.

https://doi.org/10.1016/j.foodcont.2014.03.039 
Review

\title{
Persistence of foodborne pathogens and their control in primary and secondary food production chains
}

\author{
Marianne Halberg Larsen ${ }^{\mathrm{a}}$, Marion Dalmasso ${ }^{\mathrm{b}}$, Hanne Ingmer ${ }^{\mathrm{a}}$, Solveig Langsrud ${ }^{\mathrm{c}}$, \\ Mindaugas Malakauskas ${ }^{d}$, Anneluise Mader $^{\mathrm{e}}$, Trond Møretrø ${ }^{\mathrm{c}}$, Sonja Smole Možina ${ }^{\mathrm{f}}$, \\ Kathrin Rychli ${ }^{g}$, Martin Wagner ${ }^{g}$, R. John Wallace ${ }^{\mathrm{h}}$, Jurgen Zentek ${ }^{\mathrm{e}}$, Kieran Jordan ${ }^{\mathrm{b}, *}$ \\ ${ }^{a}$ Department of Veterinary Disease Biology, University of Copenhagen, Denmark \\ ${ }^{\mathrm{b}}$ Teagasc Food Research Centre, Moorepark, Fermoy, Co. Cork, Ireland \\ ${ }^{\mathrm{c}}$ Nofima, The Norwegian Institute of Food, Fisheries and Aquaculture Research, Aas, Norway \\ ${ }^{\mathrm{d}}$ Veterinary Academy, Lithuanian University of Health Sciences, Kaunas, Lithuania \\ e Institute of Animal Nutrition, Freie Universität Berlin, Germany \\ ${ }_{\mathrm{f}}^{\mathrm{f}}$ Department of Food Science and Technology, Biotechnical Faculty, University of Ljubljana, Slovenia \\ ${ }^{\mathrm{g}}$ Institute for Milk Hygiene, Milk Technology and Food Science, University of Veterinary Medicine Vienna, Austria \\ ${ }^{\mathrm{h}}$ Rowett Institute of Nutrition and Health, University of Aberdeen, Bucksburn, UK
}

\section{A R T I C L E I N F O}

\section{Article history:}

Received 14 June 2013

Received in revised form

19 March 2014

Accepted 25 March 2014

Available online 3 April 2014

\section{Keywords:}

Foodborne pathogen

Persistence

Control

Escherichia coli

Listeria monocytogenes

Salmonella

\begin{abstract}
A B S T R A C T
This review highlights factors involved in the persistence of foodborne pathogens in selected food chains and covers aspects of the basis for persistence, the consequences of persistence in terms of food safety implications, and the strategies that can be employed to combat persistence. The examples selected are Escherichia coli 0157 and Salmonella at primary production of cattle and pigs, respectively, Listeria monocytogenes and Cronobacter spp. at secondary production, while persistence of Campylobacter spp. represents both primary and secondary production.
\end{abstract}

(c) 2014 Elsevier Ltd. All rights reserved.

\section{Contents}

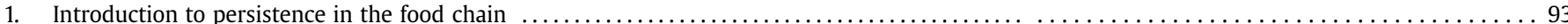

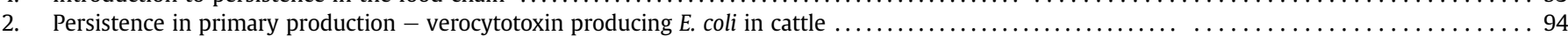

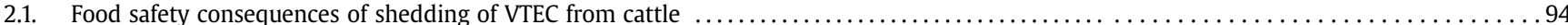

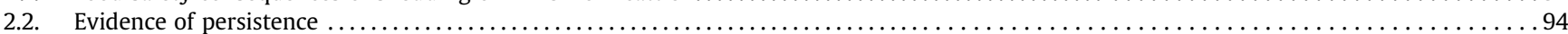

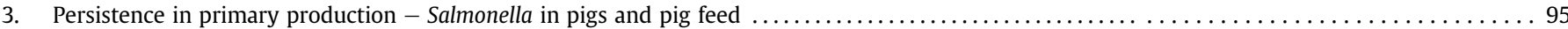

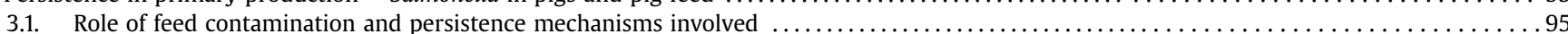

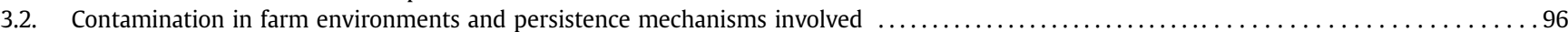

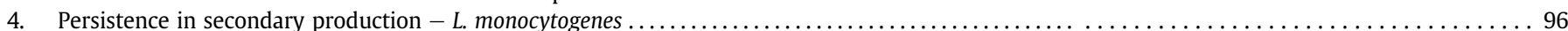

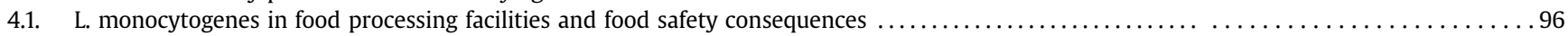

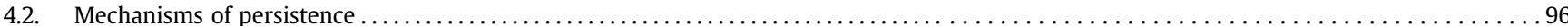

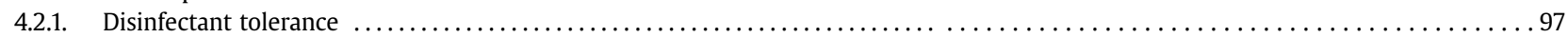

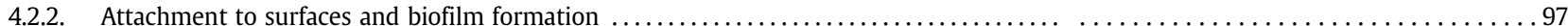

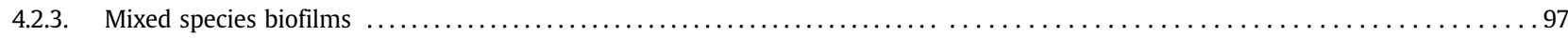

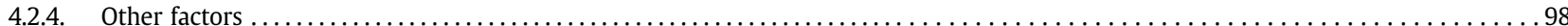

\footnotetext{
* Corresponding author. Tel.: +353 2542451; fax: +353 2542340 .

E-mail address: kieran.jordan@teagasc.ie (K. Jordan).
} 


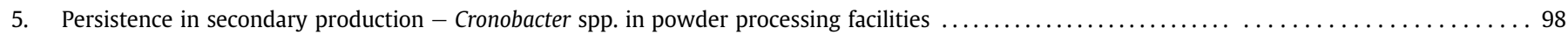

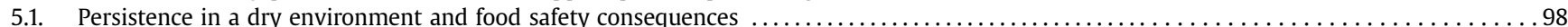

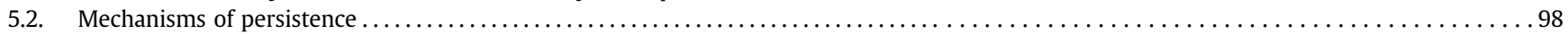

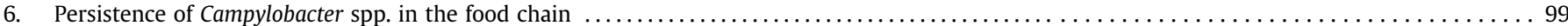

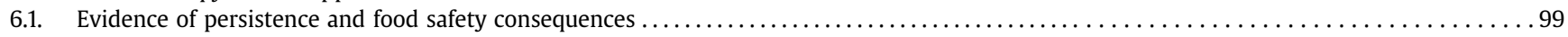

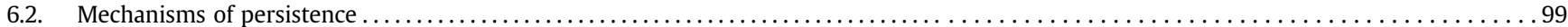

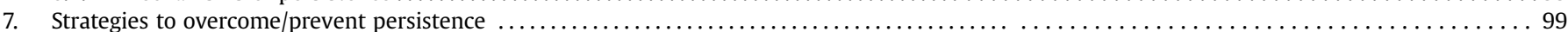

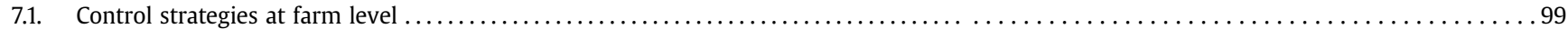

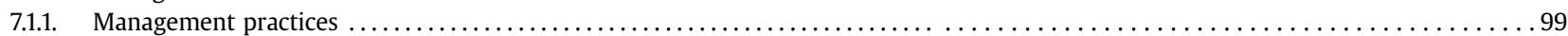

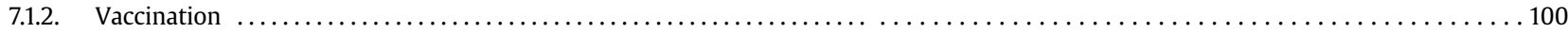

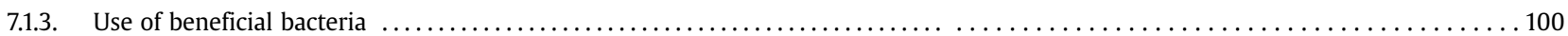

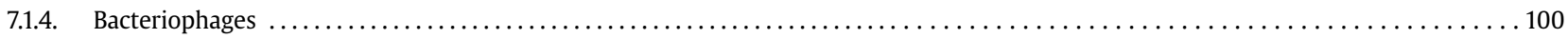

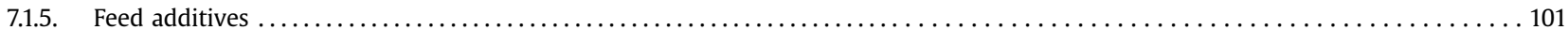

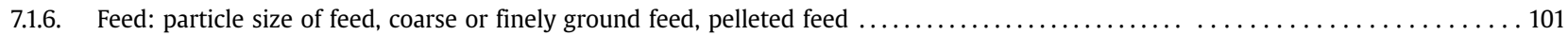

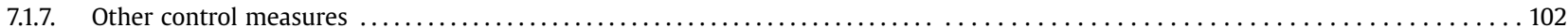

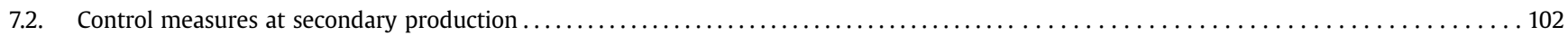

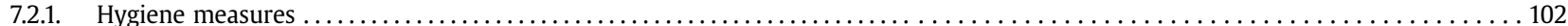

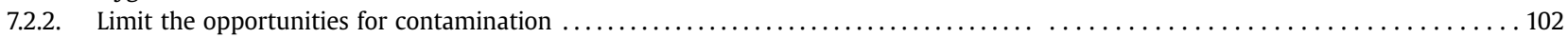

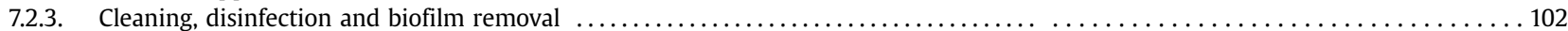

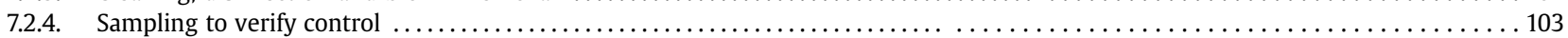

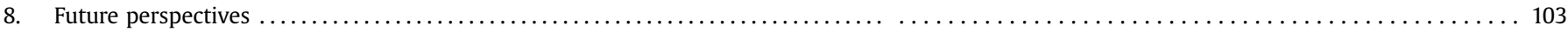

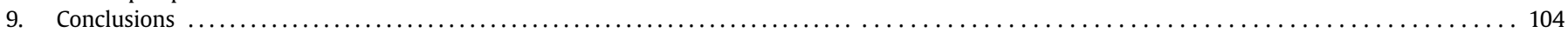

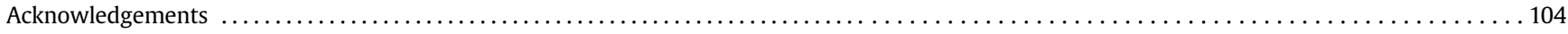

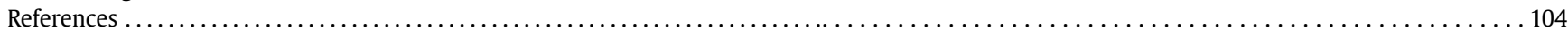

\section{Introduction to persistence in the food chain}

In recent years, the awareness of the persistence of foodborne pathogens in primary and secondary food processing environments has attracted much scientific interest in microbiology. Persistence means that particular types of microorganisms survive for prolonged periods of time in certain habitats. Persistence of a pathogen relies on many factors, such as the physical and microbial natural habitat, transmission routes and genetic determinants (Fig. 1). Persistence can cause repeated food contamination, and an increasing risk of food safety violation, thus impacting on public health (Pricope, Nicolau, Wagner, \& Rychli, 2013). Persistence always refers to a particular matrix or environment, either soil, feed, animals, farm production environments, food processing environments or food itself. If looking to transmission of food-borne pathogens, one may easily understand that pathogens travel through a sequence of ecological niches before they pose a threat to humans. A very simple example is Listeria monocytogenes that is believed to be ubiquitously spread in nature, and can colonize food processing environments through inappropriate or inadequate

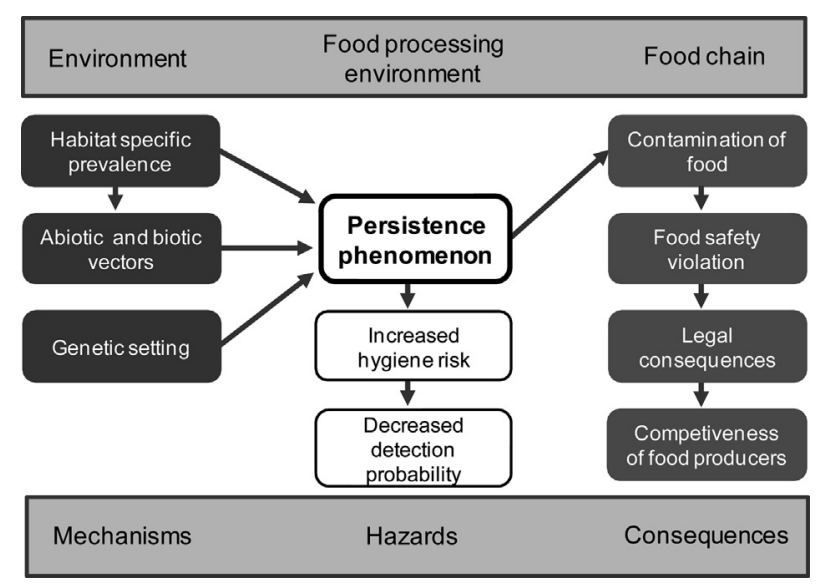

Fig. 1. Elements of persistence and the food safety consequences. hygiene, from where it can contaminate food and finally infect humans who have been exposed to contaminated food (Khelef et al., 2006). Thus, scientific disciplines such as microbial ecologists and food microbiologists should work together in a multidisciplinary approach to address the issue.

Most microbial communities are highly complex and subject to reorganisation. That some microbial communities are more stable than others implies that exposure to stress and reorganisation can lead to a more resistant population. Even under very harsh conditions, such as in the animal stomach or during high heat treatments, a surviving microbiota exists that may proliferate and pose new hazards. In contrast, some environments such as the animal intestine may be carriers of human pathogens, although they are not pathogenic to the carriers (Naylor et al., 2003). Such zoonotic strains include verocytotoxigenic Escherichia coli or shigatoxin producing Escherichia coli (VTEC or STEC, in this review we used VTEC) in cattle and Campylobacter in chickens. Understanding factors that foster creation of stable microbial communities will allow manipulation of these factors. With respect to environmental contaminants, the goal should be to understand persistence and therefore enable the development of a stable commensal microbiota not inducing persistence of pathogens, rather than placing an over-emphasis on sanitisation.

For the purposes of this review, persistence will be defined broadly and differently at primary and secondary production. At primary production, colonization of the animal is in this review perceived as persistence as it may result in shedding of the same strain of for example E. coli 0157:H7 from cattle for weeks or months, or repeated isolation of the same Salmonella strain from pigs. In addition, bacterial isolates may persist in the farm environment such as in the stable or the feed. At secondary production in the processing environment, persistence of bacterial strains refers to repeated isolation of the same strain for months or even years at the same sites (Unnerstad et al., 1996).

For the purposes of understanding the basis of persistence, it is usual to compare the behaviour and properties of persistent (also called permanent or resident) and non-persistent strains. In order to do this, the term non-persistent needs to be defined. This is more difficult as failure to isolate a strain may be due to a sampling issue 
or simple absence, rather than to an inherent property of the strain. Therefore, strains should be termed 'presumed' non-persistent or sporadic or transient. In primary production, shedding of a pathogen would be considered non-persistent if it occurred only for 1-2 days, and environmental non-persistence would be disappearance of the strain in a week, while in secondary production a 'presumed' non-persistent strain is one that is isolated only once in the process of a monthly sampling plan of 12 months.

Infections with Campylobacter spp. and Salmonella spp. are among the most often reported zoonotic diseases in humans in the EU (EFSA, 2013). Poultry and fresh pig meats are among the most important food vehicles involved in foodborne Campylobacter and Salmonella outbreaks, and much of the disease burden originates from contamination at primary production. Cases of human infections caused by VTEC or L. monocytogenes are less numerous, but due to the serious nature of the diseases caused and the high mortality rates, these infections are also very important to control. Cronobacter spp. (formerly Enterobacter sakazakii) are opportunistic pathogenic bacteria that can cause serious infections such as necrotizing enterocolitis, bacteraemia and meningitis in vulnerable neonates and infants (Hunter \& Bean, 2013; Lai, 2001; Mullane et al., 2008). However, recent reports describing cases of Cronobacter infections in immunocompromised adults including the elderly, suggest that older individuals may also be susceptible to Cronobacter infections. Within the susceptible population, the number of cases is approximately 6 per year worldwide (Healy et al., 2010). Disease caused by Cronobacter spp. is not frequent but as the mortality rate has been estimated to be up to $80 \%$ (Lai, 2001) and the main source of neonatal infections has been rehydrated powdered infant formula (Iversen, Lane, \& Forsythe, 2004; van Acker et al., 2001; Yan et al., 2012), monitoring and dealing with its occurrence and persistence in the powder-processing environment is a major concern for the dry food industry, including the infant formula industry. Thus, the most important foodborne infections either in numbers or severity are due to pathogens that have the ability to persist in the primary production or at secondary production facilities.

\section{Persistence in primary production - verocytotoxin producing $E$. coli in cattle}

Many different animal species are reservoirs for VTEC, but by far the most important animal source of human cases of infections with zoonotic VTEC is cattle (EFSA, 2012; Nataro \& Kaper, 1998). VTEC strains are categorised into a number of serogroups of which 0157 is the most widely known. Other important serogroups are 026, 091, 0103, 0111, and 0145. Serogroup 0157 is the cause of approximately half of the VTEC associated diseases in the EU and commonly associated with the most severe cases of disease i.e. haemorrhagic colitis (HC) and the potentially life threatening haemolytic uremic syndrome (HUS) (EFSA, 2008a, 2013). However, the epidemiology of VTEC may differ in different geographical regions (EFSA, 2013). In addition, the role of the pathogenic non-0157 strains in human disease and the prevalence of them in animals has begun to emerge as more laboratories begin to use detection methods for non-0157 strains (EFSA, 2012; Thomas et al., 2012).

\subsection{Food safety consequences of shedding of VTEC from cattle}

The potential routes for contamination with VTEC at farm level are shown in Fig. 2. Faecal shedding of E. coli 0157:H7 from cattle may result in contaminated food of bovine or ovine origin including meat and raw milk and derived dairy products. In addition, produce and water may become contaminated with VTEC from animal faeces. Environmental contamination and direct contact with animals play a role in human VTEC infections (Fig. 2) (Chapman, 2000; O’Brien, Adak, \& Gilham, 2001; Ogden et al., 2002). The level of excretion is important as this will affect the risk of faecal contamination in all potential contamination routes. Thus, cattle persistently shedding VTEC, particularly at high numbers, give rise to a higher prevalence of VTEC in the farm environment, creating a higher risk of contaminated food products than cattle with occasional shedding (Chapman, 2000; O'Brien et al., 2001; Ogden et al., 2002). The incidence of $E$. coli 0157:H7 infections in man and shedding of VTEC from cattle have both been well established to be seasonal (Chapman, 2000; Edrington et al., 2006; Hancock, Besser, Rice, Herriott, \& Tarr, 1997). At least part of the seasonality may be due to the greater survival/proliferation of E. coli 0157:H7 in faeces when the temperature increases (Bach, Selinger, Stanford, \& McAllister, 2005). The prevalence of E. coli 0157 displays striking variability across the cattle population (Matthews et al., 2006a). On $78 \%$ of Scottish farms, in a cross-sectional survey of 952 farms, no shedding of E. coli 0157 was detected. However, on a small proportion of farms, ca. $2 \%$, a very high prevalence of infection was found (with $90-100 \%$ of faeces samples being positive). The numbers of VTEC in the faeces of VTEC-positive cattle also varies from very low to very high. Thomas et al. (2012) found that in 130 VTEC positive faecal samples only two samples had numbers above the detection levels of $200 \mathrm{CFU} / \mathrm{g}$. These two samples had counts of 1000 and $1300 \mathrm{CFU} / \mathrm{g}$. The numbers of VTEC in faeces will affect the risk of faecal contamination of the carcasses either directly or indirectly via a contaminated hide. Lairage at the slaughterhouse (holding pens used immediately before slaughter) will increase the risk of cross contamination to other animals and subsequently onto the carcasses. The hide removal process during slaughter makes it difficult to prevent transfer of bacteria from the hide to the carcass and several studies show correlation between the incidence of pathogens on hides and on derived carcasses (Arthur et al., 2004; Baird, Lucia, Acuff, Harris, \& Savell, 2006; Barkocy-Gallagher et al., 2003; Elder et al., 2000; Jacob, Paddock, Renter, Lechtenberg, \& Nagaraja, 2010).

\subsection{Evidence of persistence}

The human health risk is, as described above, associated with the level of excretion of VTEC in the faeces. Some cattle shed very high numbers of E. coli 0157:H7 in their faeces and are known as 'super-shedders' (Chase-Topping, Gally, Low, Matthews, \& Woolhouse, 2008; Matthews et al., 2006a, 2006b). According to the definitions by Lim et al. (2007) and Carlson et al. (2009) cows are defined as super-shedders if they shed more than $10^{4} \mathrm{CFU} / \mathrm{g}$ but these so-called super-shedders may excrete as many as $10^{7} \mathrm{CFU} / \mathrm{g}$ of faeces (Fukushima \& Seki, 2004), which corresponds to $>10^{11} \mathrm{E}$. coli 0157:H7 per day. However, the concentration of VTEC in the faeces is not only associated to the levels of excretion but also to the duration of shedding (Davis et al., 2006) and super-shedders have also been defined as those animals that shed VTEC 0157:H7 for more than three consecutive months or extended periods (Lim et al., 2007). The duration of shedding varies between animals with most animals being culture positive for less than one week but few animals are culture positive for several weeks or months and these colonized animals have been suggested to contribute significantly to the pathogen load on farms (Carlson et al., 2009; Davis et al., 2006). Carlson et al. (2009) have shown that shedding of a strain with an indistinguishable pulsed field gel electrophoresis (PFGE) profile (indicating a very similar strain) can persist for up to 110 days in cattle. It was shown that $1 \%$ of feedlot cattle persistently shed strains with indistinguishable PFGE profiles. However, there has been little study on the molecular ecology of strain persistence of $E$. coli $0157: \mathrm{H} 7$ and non-O157 in cattle and further studies are 


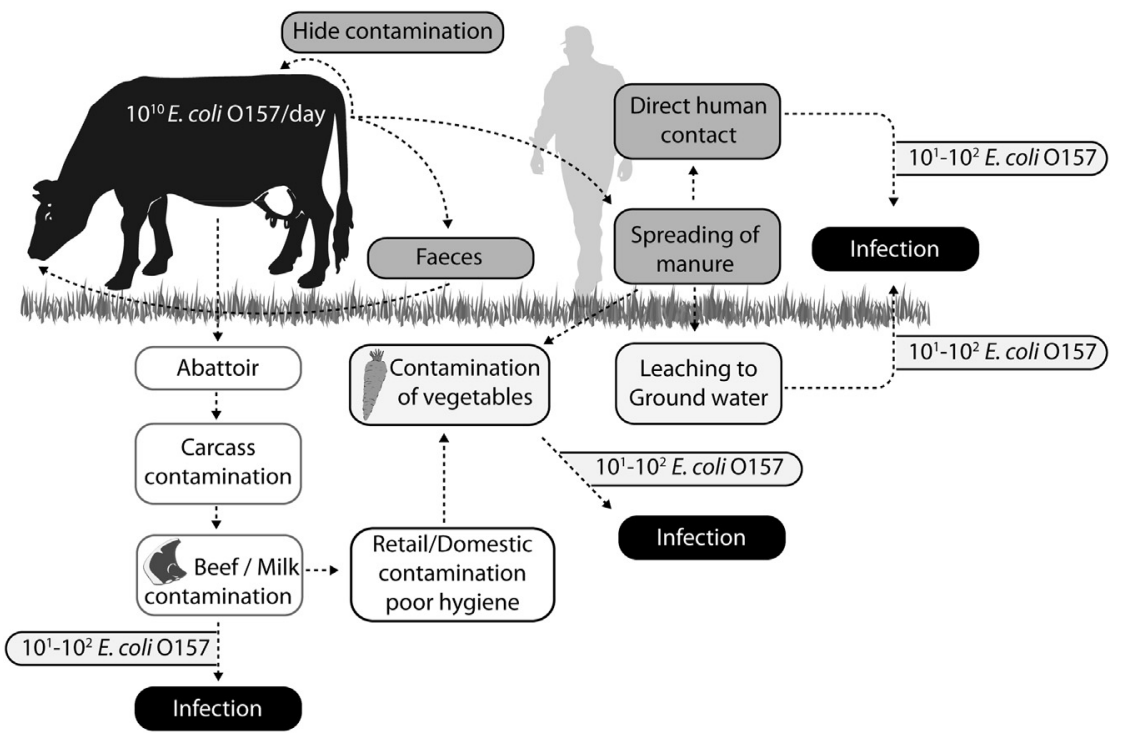

Fig. 2. Cycle of carriage of $E$. coli 0157 on farms and the pathway of infection.

needed to elucidate pathogen factors involved in persistence with VTEC strains.

E. coli $0157: \mathrm{H} 7$ can survive in cattle slurry for at least several weeks (Kudva, Hatfield, \& Hovde, 1995), and in soil for at least as long. Survival in soil depends on temperature and moisture and is considered to be a key aspect of on-farm persistence of $E$. coli 0157:H7. Soil structure and chemical content influence the persistence of E. coli $\mathrm{O} 157$ in soil. In a study of 36 Dutch arable manure-amended soils (Franz et al., 2008) concluded that E. coli O157 populations declined faster under more oligotrophic soil conditions, which can be achieved by the use of organic fertilizer with a relatively high carbon/nitrogen ratio and consequently a relatively low rate of nutrient release. Mubiru, Coyne, and Grove (2000) stated that enhancing moisture retention and fine soil particles could increase bacterial survival because of an increased ability to retain nutrients. Organic farms were not different to conventional farms. Ma et al. (2011) added different mutants of E. coli $\mathrm{O} 157$ to soils. Virulence played no part in persistence, but the different soils did: the calculated time needed to reach the detection limit for loamy sand, sandy loam, and silty clay was 32,80 , and 110 days, respectively. It has been speculated that free-living protozoa may play a role in harbouring the pathogen, particularly via the dissemination of amoeba cysts contaminated with the bacteria (Barker, Humphrey, \& Brown, 1999).

\section{Persistence in primary production - Salmonella in pigs and pig feed}

Pig meat is a significant source of human infections of Salmonella (EFSA, 2012). The Salmonella load of animals and animal products can be minimized by controlling all potential entry pathways. Food animal may acquire Salmonella infection on the farm from wild birds and rodents, but the main sources are either other animals, which may be symptomless excreters, or contaminated feed (Wierup \& Haggblom, 2010). The relative importance of different sources of Salmonella infections in animals varies. In regions with a low prevalence status of Salmonella, contaminated feed is the major source of Salmonella in the animal food production. In regions with a high prevalence in animals, the relative importance of feed compared to other sources of Salmonella may be lower (EFSA, 2008b) (Tables 1 and 2).

\subsection{Role of feed contamination and persistence mechanisms} involved

There are numerous examples of outbreaks of Salmonella infections in pigs that were traced to contaminated feed, and published data from 2010 (EFSA, 2012) indicate an occurrence of 0.5$0.7 \%$ of Salmonella in feed for pigs, poultry and cattle in the EU (Table 1). The prevalence of Salmonella in feedstuffs depends on the nature and origin of the feed material, its primary hygienic quality, the treatment and other factors during the production process.

The primary mode of contamination of feed materials is from animals defecating in the farm environment, by fertilization of crops with manure (Maciorowski, Herrera, Jones, Pillai, \& Ricke, 2007) or by recontamination with Salmonella that persist in the production and transport facilities. In addition, wild birds, rodents and insects may carry Salmonella, but the significance of these species as sources of contamination in feed factories is unclear (Davies \& Wray, 1997; Nesse et al., 2005).

Salmonella can persist in the feed processing facilities, where some serovars can be repeatedly isolated for many years. The clones may persist on parts of the factory equipment or environment (Nesse et al., 2003). If long-lasting contaminants are present, it can be assumed that the routines for decontamination have been inadequate or that the prevention of bacteria from entering the factories, or from the raw material part of the plant to the finished product has not been successful (Nesse et al., 2003).

Several mechanisms that may be the basis of persistence of Salmonella have been investigated. These include resistance to disinfection and desiccation and biofilm formation (Møretrø, Midtgaard, Nesse, \& Langsrud, 2003; Vestby, Moretro, Langsrud, Heir, \& Nesse, 2009). Earlier studies have shown that Salmonella

Table 1

Salmonella in compound feed in the European Union 2002-2010 (EFSA, 2007, 2012).

\begin{tabular}{llllll}
\hline & Year & & & \\
\cline { 2 - 5 } & 2002 & 2004 & 2006 & 2008 & 2010 \\
\hline Total positives (\%) & & & & & \\
Cattle feed & 1.3 & 0.4 & 0.7 & 0.5 & 0.7 \\
Pig feed & 0.7 & 0.7 & 0.6 & 0.6 & 0.5 \\
Poultry feed & 0.3 & 2.0 & 0.8 & 0.9 & 0.5 \\
\hline
\end{tabular}


Table 2

Salmonella in animal and vegetable derived feed materials, European Union 20022010 (EFSA, 2007, 2012).

\begin{tabular}{llllll}
\hline & \multicolumn{2}{l}{ Year } & & & \\
\cline { 2 - 6 } & 2002 & 2004 & 2006 & 2008 & 2010 \\
\hline Total positives (\%) & & & & & \\
$\quad$ Fish meal & 2.1 & 1.1 & 1.9 & 2.1 & 9.1 \\
$\quad$ Meat and bone meal & 2.9 & 1.7 & 2.3 & 1.0 & 0.6 \\
$\quad$ Cereals & 1.2 & 0.7 & 0.3 & 0.2 & 0.9 \\
$\quad$ Oil seeds and products & 5.3 & 5.7 & 2.5 & 1.8 & 1.5 \\
\hline
\end{tabular}

are not particularly resistant to disinfection or air-drying at surfaces (Møretrø et al., 2003). Because biofilm protects bacteria against environmental stress, e.g. disinfection (Ronner \& Wong, 1993), one hypothesis is that biofilm formation facilitates persistence. A correlation between persistence and biofilm formation has been described, which suggests that biofilm forming ability may be an important factor for increasing tolerance against drying processes and persistence of Salmonella in the factory environment (Vestby et al., 2009).

\subsection{Contamination in farm environments and persistence mechanisms involved}

Salmonella can survive in feed for prolonged periods of time and contaminate farm animals. In several studies, Salmonella could readily be isolated from several samples that had been stored at room temperature for up to 3 years (D'Aoust, 1977; D'Aoust \& Sewell, 1986; Ray, Jezeski, \& Busta, 1971; Rayman, D’Aoust, Aris, Maishment, \& Wasik, 1979). In another study, broth culture of $S$. Typhimurium (5.6-9.8 $\times 10^{8} \mathrm{CFU} / \mathrm{ml}$ ) was added to $70 \mathrm{~g}$ of pelleted poultry feed and the samples were stored at 11,25 , and $38^{\circ} \mathrm{C}$, with a relative humidity of 68,51 , and $27 \%$, respectively. The survival times in days were 552, 495, and 40 days, respectively (Williams \& Benson, 1978).

Salmonella can also survive and persist in soil and on pasture at the farm (Cote \& Quessy, 2005; Sinton, Braithwaite, Hall, \& Mackenzie, 2007). Various studies were conducted to determine the survival times of different Salmonella serovars (including Salmonella Typhimurium, Salmonella Dublin and Salmonella Senftenberg) and their potential to persist in slurry. Storage of inoculated samples at temperatures ranging from 1 to $20^{\circ} \mathrm{C}$ or room temperature resulted in survival for at least 65 days and up to almost a year, whereas the survival time decreased with the temperature (Burrows \& Rankin, 1970; Jones, 1976; Rankin \& Taylor, 1969; Tannock \& Smith, 1971; Thunegard, 1975). If the temperature was increased to $>45^{\circ} \mathrm{C}$ the moist heat resistance of various Salmonella serovars could be reduced to $2-48$ h (Mitscherlich \& Marth, 1984).

Taken together the data indicate that Salmonella may become persistent in the farm environment. The mechanism(s) by which this occurs remain to be elucidated. It has been well established that bacteria from colonized food animals can be transmitted to humans through the food supply. Cattle, poultry, pigs, and other food animals can be colonized with Salmonella, which have multiple routes into the food supply. Consumption of meat or poultry products contaminated with Salmonella can lead to human salmonellosis (EFSA, 2007).

\section{Persistence in secondary production - L. monocytogenes}

\subsection{L. monocytogenes in food processing facilities and food safety} consequences

L. monocytogenes is a high risk in processed ready-to-eat foods such as dairy products made from unpasteurized and pasteurized milk, ready-to-eat meat and fish products and raw vegetables and fruit (EFSA, 2013; Ferreira, Wiedmann, Teixeira, \& Stasiewicz, 2014). The bacterium is ubiquitous in the environment and may therefore be transmitted into the processing facilities by the raw materials, the workers, trucks, tools, cleaning materials or machines (Reij, Den Aantrekker, \& ILSI Europe Risk Analysis in Microbiology Task Force, 2004). The most important contamination route is from niches in equipment colonized by persistent L. monocytogenes that survive the cleaning and disinfection procedures and can then cross contaminate the food products (Fig. 3). Persistence of $L$. monocytogenes isolates has been shown at food processing facilities, often for many years (Tompkin, 2002). In addition to strains persisting at larger scale cheese production facilities (Lomonaco et al., 2009), persistence has also been documented at smaller artisan facilities (Fox, Leonard, \& Jordan, 2011a), in the salmon industry (Rorvik, Caugant, \& Yndestad, 1995; Vogel, Huss, Ojeniyi, Ahrens, \& Gram, 2001; Wulff, Gram, Ahrens, \& Vogel, 2006), in meat processing plants (Giovannacci et al., 1999; Nesbakken, Kapperud, \& Caugant, 1996) and poultry production plants (Lawrence \& Gilmour, 1995; Ojeniyi, Christensen, \& Bisgaard, 2000; Ojeniyi, Wegener, Jensen, \& Bisgaard, 1996).

\subsection{Mechanisms of persistence}

Various factors have been studied for their role in the persistence of $L$. monocytogenes strains, including disinfectant and desiccation resistance (Aase, Sundheim, Langsrud, \& Rorvik, 2000; Holah, Taylor, Dawson, \& Hall, 2002; Kastbjerg \& Gram, 2009; Vogel, Hansen, Mordhorst, \& Gram, 2010), differences in gene expression (Fox, Leonard, \& Jordan, 2011b) and biofilm formation (Djordjevic, Wiedmann, \& McLandsborough, 2002; Lunden, Miettinen, Autio, \& Korkeala, 2000; Norwood \& Gilmour, 1999). Studies relating to these, however, have not always been conclusive and strong evidence describing mechanisms of persistence remains unclear. Persistent L. monocytogenes have been shown to be involved in listeriosis infections and product recalls (Table 3).

Table 3

Partial list of listeriosis outbreaks and product recalls associated with persistent $L$. monocytogenes

\begin{tabular}{|c|c|c|c|c|c|}
\hline Strain & Source & Year & Years of persistence & Country & Reference \\
\hline F6854 & Turkey franks, Deli turkey meat & 1989 & 12 & USA & MMWR (1989); Orsi et al. (2008) \\
\hline En2 & Ice cream plant & 1990 & 7 & Finland & Miettinen, Bjorkroth and Korkeala (1999) \\
\hline La111 & Cold smoked salmon & 1996 & 6 & Denmark & Wulff et al. (2006) \\
\hline FSL N1-449 & Smoked fish processing environment & 1998 & 11 & USA & Vongkamjan, Roof, Stasiewicz, and Wiedmann (2013) \\
\hline 102-195-S1 & Food processing environment (RTE-food) & 2000 & 1.75 (21 months) & UK & Holah, Bird, and Hall (2004) \\
\hline 6179 & Cheese & 2000 & 8 & Ireland & Fox et al. (2011b) \\
\hline 4423 & Cheese smear water & 2004 & 7 & Austria & Stessl et al. (2014) \\
\hline QMP-L1-070 & Milk & 2005 & 3 & USA & Latorre et al. (2011) \\
\hline
\end{tabular}

\footnotetext{
a Related to outbreak and sporadic cases of listeriosis.
} 


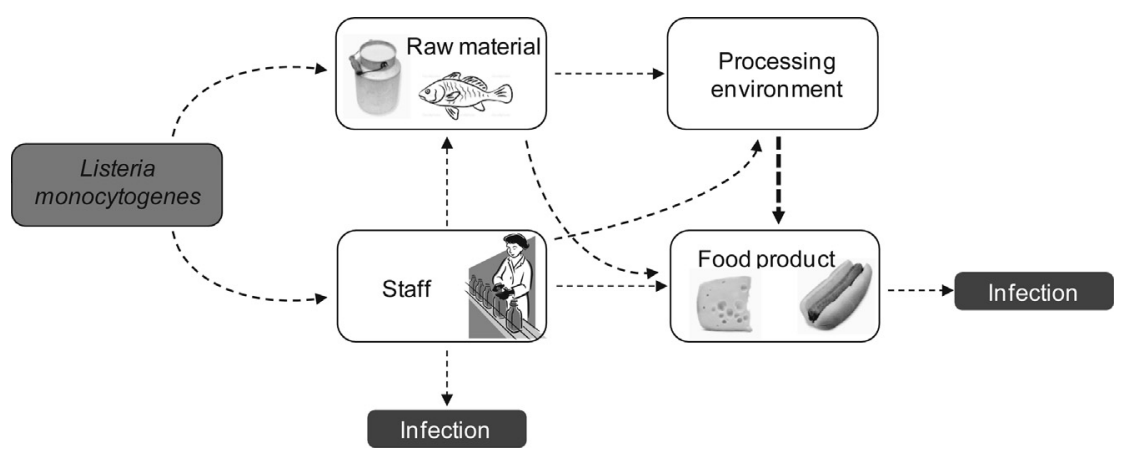

Fig. 3. Flow-chart of contamination of ready-to-eat food with L. monocytogenes.

\subsubsection{Disinfectant tolerance}

Using disinfectants at concentrations recommended for the food industry, $L$. monocytogenes in suspension will be completely inactivated (Bridier, Briandet, Thomas, \& Dubois-Brissonnet, 2011). Also, even after adaptation to a quaternary ammonium compound (QAC) based disinfectant, L. monocytogenes EGD were still sensitive at a concentration far below in-use concentrations (Kastbjerg \& Gram, 2012). Tolerance to disinfectants has been studied among groups of persistent and presumed non-persistent strains but results from different studies are contradictory. Some studies have demonstrated that persistent strains showed higher resistance than presumed non-persistent strains (Aase et al., 2000; Fox et al. 2011b; Lunden, Autio, Markkula, Hellstrom, \& Korkeala, 2003). However, even in persistent isolates a resistance-level far below user-concentrations was found (Aase et al., 2000; Fox et al., 2011b). Also, a clear link between persistence and increased disinfectant resistance was not recorded in some other studies (Holah et al., 2002; Kastbjerg \& Gram, 2009). Elhanafi, Dutta, and Kathariou (2010) identified a plasmid-based gene cassette that conferred increased resistance to benzalkonium chloride, a widely used QAC disinfectant in the food industry. In addition, a novel transposon carrying a transporter $(\mathrm{QacH})$, which is responsible for benzalkonium chloride tolerance, has been described (Muller et al., 2013). Genetic elements such as these may have significance in terms of strain persistence in some strains. It should be emphasised that measuring minimum inhibitory concentrations was used to determine the level of resistance in these studies and the results cannot be directly extrapolated to survival after disinfection. On the other hand, it cannot be ruled out that mechanisms involved in a lowlevel enhanced tolerance contribute to survival at sub-optimal disinfection conditions. Examples could be when the disinfectant is partly neutralised by organic matter from food debris or biofilms (González-Fandos, Sanz, García-Fernández, \& García-Arias, 2005; Grönholm, Wirtanen, Ahlgren, Nordström, \& Sjöberg, 1999; Pan, Breidt, \& Kathariou, 2006).

\subsubsection{Attachment to surfaces and biofilm formation}

A number of studies have investigated attachment/biofilm formation of persistent and presumed non-persistent strains of $L$. monocytogenes to surfaces, with varying results. The varying results may be as a result of different methods used, and the fact that many studies refer to biofilm formation as occurring in a few hours (which is really attachment) whereas actual biofilm formation may take several days. Differences in strains, culture medium, physiochemical properties of the environmental surfaces and time of the experiment could impact these results and explain the different results as pointed out by Carpentier and Cerf (2011). Norwood and Gilmour (1999) found statistically greater mean adherence ability among persistent strains compared to presumed non-persistent strains. However, the results were not entirely consistent as some individual non-persistent strains showed high adherence. Using a microtitre plate assay method, Djordjevic et al. (2002) did not find higher adherence among persistent strains. In a study by Lunden et al. (2000), it was shown that persistent strains showed enhanced attachment over short periods of time, however, some presumed non-persistent strains matched, or in some cases surpassed, the levels of attachment of persistent strains after $72 \mathrm{~h}$. A possible explanation for this observation may involve differences in flagella between different strains; flagella have been shown to facilitate early attachment to stainless steel (Vatanyoopaisarn, Nazli, Dodd, Rees, \& Waites, 2000). A recent study found better adherence of persistent strains from dairy environment than sporadic strains (Latorre et al., 2011). Higher biofilm formation among persistent compared to non-persistent strains from bulk milk samples was also described (Borucki, Peppin, White, Loge, \& Call, 2003). It has been speculated that attachment affects the susceptibility to disinfectants, but Kastbjerg and Gram (2009) found no difference between attached and planktonic cells. However, other studies showed increased resistance to disinfection of L. monocytogenes in biofilm compared to in suspension and in several studies resistance was observed to user-concentrations of disinfectants (Annous, Fratamico, \& Smith, 2009). However, it should be pointed out that in most of these studies, biofilms are disinfected without a prior cleaning step, which is included in the normal routine in the food industry. Cleaning is supposed to remove the majority of the biofilm. Typically, thick biofilms will not form on smooth food contact surfaces subjected to daily cleaning and disinfection, but are more likely to form in areas not as thoroughly cleaned (like floors and walls where there can be crevices or cracks), or on equipment difficult to clean (Holah \& Gibson, 2000). Latorre et al. (2009) conducted a study monitoring the epidemiology of $L$. monocytogenes strains on a dairy farm, in which they postulated that biofilm formation was responsible for repeated contamination events during the study period. The work, including typing of $L$. monocytogenes strains isolated from bulk milk and milking equipment, and examination of biofilm on the milking equipment, supported the view that the ability of $L$. monocytogenes to form biofilm is important in persistence of strains.

\subsubsection{Mixed species biofilms}

The examples above focus on the link between persistence and biofilm formation examined for pure bacterial cultures. However, bacteria dominating in the food production environment are typically non-pathogenic species of Pseudomonas, Acinetobacter and Staphylococcus (Bagge-Ravn et al., 2003; Marouani-Gadri, Augier, \& Carpentier, 2009), thus pathogenic bacteria in a biofilm will most likely be a part of a multispecies biofilm and the ability of a strain to co-exist in multispecies biofilms may be important for its persistence in the production environment. It has been shown that biofilm formation of L. monocytogenes can both be inhibited (Jeong \& Frank, 
1994) and promoted in multispecies biofilms (Sasahara \& Zottola, 1993). In addition, biofilm formation may be influenced by other L. monocytogenes strains present as the growth of a low biofilm producing strain was increased in the presence of a stronger biofilm producing strain (Pan, Breidt, \& Kathariou, 2009). Pathogens (for example $L$. monocytogenes) present in multispecies biofilms may have increased protection against disinfection (Norwood \& Gilmour, 2000; Van der Veen \& Abee, 2011). Extracellular polysaccharide (EPS) production can limit the effectiveness of disinfectants, and mixed biofilms may play a role in persistence of $L$. monocytogenes if other organisms producing EPS are present in biofilm with L. monocytogenes (Bremer, Monk, \& Osborne, 2001; Carpentier \& Cerf, 2011). At present, the role of multispecies biofilms for persistence of L. monocytogenes is not clear and a comparison of clones with different persistence potential for their ability to survive in multispecies biofilms would give important information.

\subsubsection{Other factors}

In addition to biofilm forming capacity and disinfection tolerance, other factors could influence the persistence phenomenon at secondary production alone or in combination. These include reintroduction of the "persistent" strain-type from an external habitat, increased survival and growth capacity at the conditions in the processing environments including low temperature, specific food sources, high salt concentrations, nutrient limitation and competition. One example is the comparison of gene expression of persistent and presumed non-persistent strains showing upregulation of a variety of genes such as the $p d u, c o b-c b i$, and eut gene clusters in persistent strains when compared with nonpersistent strains. These genes have implications for utilisation of carbon sources, which may confer a competitive advantage, promoting persistence of the strain (Fox et al., 2011b). It is also possible that persistence of $L$. monocytogenes is a more complex issue, which can vary from strain to strain (Fox et al., 2011b). Verghese et al. (2011) proposed a model for rapid niche-specific adaptation and persistence of $L$. monocytogenes involving integration of prophage DNA into the comK gene of $L$. monocytogenes. Defective comK prophage was replaced with the rapid adaptation island (RAI). Natural selection then acts on RAI recombinants to yield unique persistent prophage types that are adapted to the specific environment at individual processing plants (Verghese et al., 2011).

It has been suggested that persistence is simply due to harbourage sites that are not sufficiently sanitised, and thus lead to recontamination events by strains resident in these sites (Carpentier \& Cerf, 2011). These sites include slots, drains, slicers, conveyer belts, and packaging machines.

Another possible mechanism of persistence may be by internalisation of $L$. monocytogenes strains inside protozoa, which can encyst to survive harsh conditions such as drain water. If L. monocytogenes can internalise in protozoa they could be protected from otherwise lethal environmental conditions, and thus persist (Greub \& Raoult, 2004). One study reported that L. monocytogenes, upon ingestion by protozoa, is capable of survival, and is released after a few days due to lysis of the protozoa (Ly \& Muller, 1990). In contrast, it has recently been shown that L. monocytogenes is unable to persist in Acantamoeba (Doyscher, Fieseler, Dons, Loessner, \& Schuppler, 2013).

\section{Persistence in secondary production - Cronobacter spp. in powder processing facilities}

Cronobacter spp. are widespread in the environment, although a specific reservoir remains to be identified. They have been detected from a wide variety of sources, including in several dry food processing facilities, in retail bakeries, different types of mainly dry foods and powdered ingredients, animal feed, different vegetables, herbs and spices, rice and in the environment (Beuchat et al., 2009; Kandhai, Reij, Gorris, Guillaume-Gentil, \& van Schothorst, 2004; Walsh et al., 2011). However, the frequency with which they are isolated is generally low, except in the case of dried food matrices (Molloy et al., 2009), including powdered infant formula (Osaili \& Forsythe, 2009). Dairy cattle and raw milk do not, however, seem to be a dissemination route (Molloy et al., 2009).

\subsection{Persistence in a dry environment and food safety consequences}

The majority of cases of disease due to Cronobacter are susceptible infants becoming infected following consumption of contaminated reconstituted powdered infant formula (Norberg et al., 2012). Cronobacter spp. appear to be adapted to survive in low water activity matrices and environments, sometimes extending over considerable time periods. In general the level of contamination is low but after rehydration Cronobacter may rapidly grow to critical levels if the reconstituted product is temperature abused. Survival in dehydrated powdered infant formula, where the water activity is about 0.2 , for up to two years and in infant cereal for up to 24 weeks has been shown (Edelson-Mammel, Porteous, \& Buchanan, 2005; Gurtler \& Beuchat, 2007a, 2007b; Lin \& Beuchat, 2007a, 2007b). Persistence of desiccated Cronobacter depends on water activity and temperature with less survival with increasing temperature $\left(30^{\circ} \mathrm{C}\right.$ compared to $\left.4{ }^{\circ} \mathrm{C}\right)$ and higher water activities ( $a_{\mathrm{w}} 0.43-0.5$ compared to $a_{\mathrm{w}} 0.25-0.3$ ). The unknown reservoir of this pathogen challenges the control of its entry into food products. Cronobacter can survive the actual spray drying process (Arku, Mullane, Fox, Fanning, \& Jordan, 2008), but is unlikely to survive heat treatments prior to that and thus its presence in the final formula may be due to its presence in un-heat treated raw material or recontamination from the processing environment. Cronobacter spp. can persist in dry food processing and preparation environments such as powdered infant formula processing environments (Hein et al., 2009; Mullane et al., 2008; Proudy, Bougle, Leclercq, \& Vergnaud, 2008), but also in retail confectionery shops, and other dry food facilities for example chocolate, potato and pasta factories (Baumgartner, Grand, Liniger, \& Iversen, 2009; Kandhai et al., 2004). Proudy et al. (2008) subtyped 200 Cronobacter isolates from a powdered infant formula factory and found that $70 \%$ of the isolates were clonally identical. Epidemiologically, powdered infant formula and the environment in which it is produced have been linked with transmission of disease to neonates (Himelright et al., 2002; Nazarowec-White \& Farber, 1999) where among other things, air filters were shown to be a source of contamination (Mullane et al., 2008).

\subsection{Mechanisms of persistence}

The prevalence of Cronobacter in these low water activity products and corresponding processing environments also during prolonged storage shows that Cronobacter has the capacity to adapt to, survive and persist under desiccated environmental conditions (Beuchat et al., 2013; Walsh et al., 2011). The mechanism behind the unique ability of Cronobacter to survive desiccation is not fully understood and studies investigating the mechanism are limited. However, Cronobacter has cross-resistance to dry and thermal stresses (Dancer, Mah, Rhee, Hwang, \& Kang, 2009). Proteomic analysis showed that genes upregulated during desiccation stress included proteins that serve some structural or protective role and down-regulation of the motility-associated proteins (Riedel \& Lehner, 2007). Survival in a dry environment was also studied by Breeuwer, Lardeau, Peterz, and Joosten (2003), who concluded that uptake of ions (calcium, for example) and compatible solutes (for 
example, trehalose) can increase intracellular osmolarity (Kempf \& Bremer, 1998) and thus survival. The sequences of the recently sequenced Cronobacter sakazakii BAA-894 and of sixteen other strains show a number of genes associated with neonatal infection, including copper and silver resistance mechanisms known to be important for invasion of the blood-brain barrier (Grim et al., 2013; Joseph et al., 2012; Kucerova et al., 2010; Shin, Lee, Choi, \& Ryu, 2012; Shin, Lee, Kim, \& Ryu, 2012; Stephan, Lehner, Tischler, \& Rattei, 2011; Yan et al., 2013). Subsequent mining of the genome data will facilitate an understanding of the persistence of Cronobacter spp. and the development of methods to inactivate persistent clones.

\section{Persistence of Campylobacter spp. in the food chain}

Campylobacter spp., especially Campylobacter jejuni and Campylobacter coli, are the most commonly reported bacterial causes of food-borne gastroenteritis in humans worldwide, usually transmitted to humans via consumption of undercooked food, unpasteurized milk, or contaminated RTE food or via water. Besides their widespread occurrence, Campylobacter strains have become increasingly resistant to antibiotics (Smole Možina, Kurinčič, Klančnik, \& Mavri, 2011), including the major drugs of choice for treatment of clinical campylobacteriosis. This could reduce the effectiveness of treatments, but could also influence their persistence in food production chains.

\subsection{Evidence of persistence and food safety consequences}

Molecular approaches, such as PFGE, have shown persistence of Campylobacter spp. in the whole food production chain from the farm to the retail product (Damjanova et al., 2011; Eberle \& Kiess, 2012; Lienau, Ellerbroek, \& Klein, 2007; Melero, Juntunen, Hanninen, Jaime, \& Rovira, 2012). Persistence was reported on farms and in the well-water supplied to the farms (Perez-Boto et al., 2010). Characteristic prevalent clones have been found in the majority of poultry flocks and their transmission between consecutive flocks demonstrated (Damjanova et al., 2011; Petersen \& Wedderkopp, 2001). Persistent strains were shown to be transferred from the flock to carcasses after slaughter (Wirz, Overesch, Kuhnert, \& Korczak, 2010) or even from the farm to retail products (Melero et al., 2012). Besides this, cross-contamination at different points, e.g. including poultry transportation crates, different slaughtering steps, especially scalding, defeathering and evisceration and also at retail (e.g. market places), was reported despite periodic sanitation procedures at all these steps (Hastings, Colles, McCarthy, Maiden, \& Sheppard, 2011; Melero et al., 2012; Peyrat, Soumet, Maris, \& Sanders, 2008; Zorman, Heyndrickx, Uzunovic-Kamberovic, \& Mozina, 2006). Contamination of working surfaces and equipment during slaughter of a positive flock can persist and lead to contamination of negative flocks even after cleaning and disinfection. A similar situation was described for broiler (Peyrat et al., 2008) and turkey (Perko-Makela et al., 2009) production chains, mainly with $C$. jejuni, but also for the transmission of $C$. coli in pig breeding (Jensen, Dalsgaard, Baggesen, \& Nielsen, 2006) and pork meat processing environments both in conventional and organic and/or antibiotic free production systems (Abley, Wittum, Funk, \& Gebreyes, 2012; Quintana-Hayashi \& Thakur, 2012).

\subsection{Mechanisms of persistence}

Many reports illustrate persistence of at least some strains at specific points in the food chain. Whether certain clonal groups, and which ones repeatedly contaminate and have the potential to persist on farms, slaughterhouses or even market places and kitchens, needs further investigation. Similar to L. monocytogenes, some studies with Campylobacter have proposed that persistence could be related to disinfectant resistance (Mavri, Kurincic, \& Smole Mozina, 2012; Mavri \& Smole Možina, 2012; Peyrat et al., 2008) or to antibiotic resistance, which has been recognized as an emerging risk in chicken (Habib, Miller, Uyttendaele, Houf, \& De Zutter, 2009) and pork meat processing (Luangtongkum et al., 2009; QuintanaHayashi \& Thakur, 2012). Antibiotic resistance acquired through chromosomal mutations could confer survival ability on the bacteria in the absence of antibiotic selection pressure, which could result in the spread and persistence of antimicrobial-resistant Campylobacter (Zhang, Sahin, McDermott, \& Payot, 2006).

Although many stress response genes are noticeably absent in C. jejuni (Murphy, Carroll, \& Jordan, 2006), they can survive hurdles during food processing and preparation. The differences in survival ability were linked to the strain diversity, revealed by multi locus sequence typing (MLST) (Habib, Uyttendaele, \& De Zutter, 2010), to antibiotic resistance mutations (González \& Hänninen, 2012) as well as to protective environment, like chicken meat juice (Ligowska, Cohn, Stabler, Wren, \& Brondsted, 2011) and combinations of stresses (Klancnik et al., 2009; Klancnik, Vuckovic, Plankl, Abram, \& Smole Možina, 2013). However, a direct link of a stress response and subsequent enhanced survival to persistence in the food chain is not clear and should be further studied.

Beside the reasons already mentioned, Campylobacter persistence may also be linked to its biofilm forming potential. It has been suggested that the presence of biofilms in water distribution systems is responsible for the colonization of the bacteria in poultry flocks and that $C$. jejuni can persist in these aquatic environments. Thus, biofilms are likely to represent an important reservoir for C. jejuni (Ica et al., 2012). In different studies, multispecies biofilms were shown to be more robust and protective for Campylobacter persistence (Ica et al., 2012; Sanders, Boothe, Frank, \& Arnold, 2007; Teh, Flint, \& French, 2010), similar to that reported by many authors for other types of multispecies biofilms (Smole Možina, Klančnik, \& Raspor, 2013).

Similar to L. monocytogenes, protozoan cells are suspected to serve as persistent reservoirs for other bacterial pathogens, including campylobacters (Snelling, McKenna, Lecky, \& Dooley, 2005). The most recent reports suggest that depletion of dissolved oxygen by Acanthamoeba castellanii is a major factor in the observed amoeba-mediated growth enhancement of Campylobacter (Bui et al., 2012). However, the interactions of $C$. jejuni and protozoan cells such as A. castellanii are complex and multifactorial, but pre-exposure to various stresses does not confer a competitive advantage on $C$. jejuni for survival within A. castellanii. Further research on Campylobacter-protozoan interactions is required in order to gain a full understanding of this relationship and how it influences persistence.

\section{Strategies to overcome/prevent persistence}

At both primary and secondary production there are many strategies that attempt to reduce the pathogen load of feed and food. Some of these strategies are aimed at a general reduction in pathogens, while others are specifically aimed at particular pathogens. In general, control procedures will reduce numbers of all pathogens, and not necessarily only persistent strains.

\subsection{Control strategies at farm level}

\subsubsection{Management practices}

Farm management practices, including hygiene, are an important part of a pathogen control strategy on the farm. General 
management practices include maintenance of equipment, upkeep of buildings, a sanitation plan, pest control and general hygiene. Overall, it is important to control possible entries of pathogens into the farm and stables and prevent transmission and persistence within the farm with a good biosecurity plan. One example of a site with high risk of contamination is purchase, transport and mixing of feed on farms depending on the equipment and its sanitary status (Binter et al., 2011). Feed storage is also important because of the potential of contamination under improper conditions. Ideally, ingredients and compound feeding stuffs used on farms should be stored in sealed containers. It was shown on Scottish farms, that approximately 80 rodent and 25 bird faeces were deposited per $\mathrm{m}^{2}$ of stored feed per month over the winter period (Daniels, Hutchings, \& Greig, 2003). Wild birds, pets, rodents and insects in the farm environment can be carriers of pathogens like Salmonella and Campylobacter and downstream contamination can result in an elevated prevalence of infection with these bacteria (Hald, Sommer, \& Skovgaard, 2007; Warnick, Crofton, Pelzer, \& Hawkins, 2001). Effective cleaning of stables including feeding and water equipment between batches of animals/pigs is another important factor in controlling Salmonella on pig farms, but is difficult and requires special procedures (EFSA, 2008a). Also the occurrence of L. monocytogenes can be reduced with increased farm hygiene (Fox et al., 2009). Similarly, the occurrence of Campylobacter in poultry houses can be prevented by application of enhanced hygiene and biosecurity measures together with complementary interventions (feed additives, etc.) (Newell et al., 2011). However, there is still no one effective strategy available to prevent or to reduce Campylobacter prevalence in poultry flocks (Hermans et al., 2011; Lin, 2009).

\subsubsection{Vaccination}

E. coli $\mathrm{O} 157: \mathrm{H} 7$ colonizes its host by producing several proteins such as the translocated intimin receptor (Tir) and the needle elongation filament protein, EspA, that are secreted by a type III secretion system (Naylor et al., 2005). These proteins play a role in colonization of the intestine, suggesting that they might be useful targets for the development of a vaccine to reduce numbers of this organism in cattle. Vaccination of cattle with proteins secreted by E. coli 0157:H7 significantly reduced the numbers of bacteria shed in faeces, the numbers of animals that shed, and the duration of shedding in an experimental challenge model (Potter et al., 2004). Subsequent trials, however, with the same vaccine proved less successful in eliminating E. coli 0157:H7 from feedlot pens (Van Donkersgoed, Hancock, Rogan, \& Potter, 2005). Vaccination against the $\mathrm{H} 7$ flagellin may be an alternative strategy to control E. coli 0157:H7 numbers (McNeilly et al., 2008). Localized mucosal antibody responses at the rectum may also be useful as a control mechanism (Nart et al., 2008). Vaccination against Salmonella is another strategy that has been used in chicken (Desin, Koster, \& Potter, 2013), pigs (De Busser, De Zutter, Dewulf, Houf, \& Maes, 2013), and cattle (Nielsen, 2013).

Currently, there is no vaccine designed to control Campylobacter spp. in poultry. Live attenuated vaccines, killed whole-cell vaccines and subunit vaccines have been investigated for effective control of this pathogen in humans and chickens. One of the reasons for the absence of commercially available vaccines is that Campylobacter spp., unlike other foodborne pathogens, are easily transformed and show a high level of genetic diversity (Jagusztyn-Krynicka, Laniewski, \& Wyszynska, 2009). Recent studies on the use of small immunodominant peptide epitopes of Cj0113 inserted into the genomic DNA of the Salmonella vector revealed that it triggers a strong immune response what leads to a decreased Campylobacter numbers up to below detectable levels following challenge with C. jejuni (Layton et al., 2011). However, the mechanism of treatment was not examined in that study and further investigations are needed for a better understanding of the protection mechanisms afforded by vaccination with attenuated Salmonella-vectored Cj0113. Another approach used in the study done by Clark et al. (2012) revealed a promising up to $91 \%$ immune protection against C. jejuni challenge in comparison to unvaccinated and wild-type Eimeria tenella vaccinated controls when specific pathogen free chickens were vaccinated by single or multiple oral inoculation of E. tenella-CjaA oocysts. Promising results were also obtained after vaccination of chickens with an Salmonella enterica serovar Typhimurium $\Delta$ aroA vaccine expressing the $C$. jejuni amino acid binding protein $\mathrm{CjaA}$ as a plasmid-borne fusion to the C-terminus of fragment $C$ of tetanus toxin (Buckley et al., 2010). Protection induced by CjaA-specific serum IgY and biliary IgA significantly reduced the caecal number of $C$. jejuni by $1.4 \log$ CFU/g at three and four weeks post-challenge relative to age-matched unvaccinated birds. Despite promising results from most of such type studies, an effective vaccine able to reduce Campylobacter colonization in poultry and available commercially is still at the development stage.

\subsubsection{Use of beneficial bacteria}

For reasons of safety and convenience, probiotics would be an ideal solution to the problem of pathogens at farm level (Roselli et al., 2005). Probiotics can be defined as viable micro-organisms which, after sufficient oral intake, lead to beneficial effects for the host by modifying the intestinal microbiota. Strains of Lactobacillus acidophilus, L. salivarius subsp. salivarius, L. pentosus, L. murinus and Pediococcus pentosaceous as well as yeast strains have been used as probiotics (Brashears, Galyean, Loneragan, Mann, \& Killinger-Mann, 2003; Brashears, Jaroni, \& Trimble, 2003; Casey et al., 2007; Stephens, Loneragan, Chichester, \& Brashears, 2007; Swyers, Carlson, Nightingale, Belk, \& Archibeque, 2011). At present, documentation for the effect of using probiotics to inhibit pathogens are lacking and therefore use of probiotics for reduction and/or elimination of pathogens is not yet widely used.

Several studies have shown that the use of undefined or predefined bacterial mixtures can effectively prevent Campylobacter colonization of chicken intestines. Such competitive exclusion can be used as a control measure against colonisation of birds by Campylobacter spp. (Hakkinen \& Schneitz, 1999; Soerjadi, Snoeyenbos, \& Weinack, 1982; Stern, Cox, Musgrove, \& Park, 2001). However, a few studies propose that this prophylactic measure does not reduce colonization rates for $C$. jejuni in poultry (Laisney, Gillard, \& Salvat, 2004; Stern, Bailey, Blankenship, Cox, \& McHan, 1988) but application of this measure can efficiently reduce count of campylobacters in poultry intestines. The study of Hakkinen and Schneitz (1999) showed that even colonisation rate was not reduced considerably by application of a commercial lyophilised competitive exclusion product for prevention of Salmonella in broilers but was very efficient by reducing the Campylobacter counts by up to 9-log, depending on the trial. If a 2$\log$ reduction of the Campylobacter counts is achieved on the chicken carcasses it further leads to the reduced incidence of human campylobacteriosis associated with consumption of chicken meals (Rosenquist, Nielsen, Sommer, Norrung, \& Christensen, 2003). Competitive exclusion in combination with other preventive measures may explain the low prevalence of Campylobacter in broiler flocks in Finland (Perko-Makela, Hakkinen, HonkanenBuzalski, \& Hanninen, 2002).

\subsubsection{Bacteriophages}

Several studies have been conducted to examine the possible effectiveness of bacteriophage treatment in suppressing Salmonella numbers in pigs and E. coli 0157:H7 numbers in the ruminants. In pre-processing of pigs, cecal numbers of Salmonella were significantly $(P<0.05)$ reduced when a bacteriophage cocktail was 
administered to pigs along with a strain of $S$. Typhimurium (Wall, Zhang, Rostagno, \& Ebner, 2010), thus potentially reducing the occurrence of Salmonella during processing.

Similarly, bacteriophages can be used to reduce E. coli $0157: \mathrm{H} 7$ in cattle. In a rumen model, Rivas et al. (2010) showed that bacteriophage significantly $(P<0.05)$ reduced the numbers of $E$. coli 0157:H7. However, further work is required to demonstrate a reduction of $E$. coli $0157: \mathrm{H} 7$ shedding in bacteriophage animal trials (Rivas et al., 2010). In a different approach, Coffey et al. (2011) showed that bacteriophages can be effective in reduction of $E$. coli 0157:H7 on cattle hides, thus potentially reducing the numbers of E. coli 0157:H7 during slaughter and subsequently reducing cross contamination and improving food safety. Three lytic bacteriophages active against E. coli 0157:H7 were also isolated (Kudva, Jelacic, Tarr, Youderian, \& Hovde, 1999), but their activity only under highly aerobic conditions would limit their usefulness in vivo. This may explain the apparently contradictory results obtained for in vivo animal trials and trials showing reduction on hides. Sheng, Knecht, Kudva, and Hovde (2006) isolated a broad host-range bacteriophage that, in combination with other bacteriophage, eliminated E. coli 0157:H7 in experimental infections in mice and lowered shedding when applied rectally to cattle. Thus, further work is required to definitively show the efficacy of bacteriophage for $E$. coli 0157:H7 reduction in cattle. One of the main issues to be resolved is that bacteriophage resistance can set in rapidly, so many different bacteriophages will be needed for lasting efficacy, which in turn can lead to interactions between bacteriophages making some of them ineffective (Raya et al., 2011).

Bacteriophage application was reported to be successful also against Campylobacter in chickens (Loc Carrillo et al., 2005; Wagenaar, Van Bergen, Mueller, Wassenaar, \& Carlton, 2005). The reductions observed in the Campylobacter levels of the colonized birds following bacteriophage administration were between 1.5 and $5 \log \mathrm{CFU} / \mathrm{g}$ of intestinal contents compared with controls. Similar reductions in Campylobacter numbers were observed later using a different group III bacteriophage (Scott et al., 2007), and with group II bacteriophages (Carvalho et al., 2010; El-Shibiny et al., 2009).

The efficacy of bacteriophages against Campylobacter was also tested also on meat surfaces (El-Shibiny et al., 2009; Orquera, Golz, Sparborth, Joldic, \& Alter, 2012; Wagenaar et al., 2005) and against Campylobacter biofilms. The treatments led to a 1 to $3 \log$ reduction of the viable cell counts under microaerobic conditions and dispersal of biofilm matrix (Siringan, Connerton, Payne, \& Connerton, 2011). However, quick evolution of phage resistance could limit practical applications, and in addition, the mechanism(s) of action need to be understood.

\subsubsection{Feed additives}

Many early studies investigated the possibility of feed additives to control numbers of $E$. coli $0157: \mathrm{H} 7$ in the rumen. Conventional feed additives such as the ionophores, which selectively inhibit growth of Gram-positive bacteria (Chen \& Wolin, 1979), are ineffective against E. coli (Edrington et al., 2003). Antimicrobials, including oxytetracycline and neomycin, were found to lower numbers (Alali, Sargeant, Nagaraja, \& DeBey, 2004), but their widespread application would lead to concerns about introducing transmissible antibiotic resistance to human pathogens.

Essential oils are widely used in ruminant nutrition as feed additives (Benchaar et al., 2008; Wallace, 2004), and various essential oils have been shown to be toxic to $E$. coli 0157 : $\mathrm{H} 7$ in vitro (Burt \& Reinders, 2003), and S. Typhimurium (Si et al., 2006). Feed with essential oils was shown to reduce intestinal Salmonella colonization in broilers (Alali, Hofacre, Mathis, \& Faltys, 2013). Natural products such as coumarins were identified as toxic to
E. coli 0157:H7 (Duncan et al., 2004), but none have found widespread acceptance for various reasons, including safety and efficacy.

Short chain organic acids such as formic, propionic or sorbic acid and their salts can have antimicrobial effects and have been used for a long time for the preservation of feed on farms (Wales, Allen, \& Davies, 2010). It is well known, that Salmonella are sensitive to organic acids and that those additives can reduce numbers and therefore prevent re-contamination of feed during storage. Another reason to use organic acids as feed additives is the positive influence on animal health and performance. Some epidemiological studies show that pig farms using organic acids have a lower prevalence of Salmonella (Kamphues et al., 2007). There are however some contradictory results of epidemiological studies probably due to the fact that organic acids are dosed differently and the efficacy is dependent on the time factor, the duration of application and feed composition. Liquid feed may contain ingredients such as corn cob mix with a higher acid concentration and in addition the buffering capacity of different types of feed may differ significantly. Potassium diformate was shown to have the potential to reduce Salmonella excretion in pigs (Dennis \& Blanchard, 2004). Coarse feed structure and potassium diformate were able to reduce Salmonella excretion of infected piglets, some combined effects could be observed (Papenbrock, Stemme, Amtsberg, Verspohl, \& Kamphues, 2005). Medium chain fatty acids might also be of interest for the reduction of Salmonella shedding due to their potential of antimicrobial activity in the upper gastrointestinal tract (Deschepper, Bruggeman, \& Molly, 2005; Skanseng et al., 2010).

Similarly, organic acids could also be used as feed additives to reduce Campylobacter prevalence in poultry flocks with different level of efficiency. The studies showed that the high level of lactic acid in combination with a low $\mathrm{pH}$ and caprylic acid can reduce susceptibility of poultry to Campylobacter infection and reduce colonization rates within broiler flock (Heres, Engel, Urlings, Wagenaar, \& van Knapen, 2004; Solis de Los Santos et al., 2008). Also, the addition of a medium-chain fatty acid mixture to the feed increased resistance of broilers to Campylobacter colonization (Van Gerwe et al., 2010). However, there are contradictory studies including discrepant in vitro and in vivo results (Skanseng et al., 2010; Van Deun, Haesebrouck, Van Immerseel, Ducatelle, \& Pasmans, 2008) and further studies are required for the development of useful tools for the reduction of Campylobacter colonization in broiler flocks (Van Gerwe et al., 2010).

\subsubsection{Feed: particle size of feed, coarse or finely ground feed, pelleted feed}

Feed structure is an important parameter that affects the prevalence of Salmonella. The majority of studies indicate that finely ground feed and pelleting can increase the risk of Salmonella prevalence in fattening pigs (Kamphues et al., 2007). The reason for this may be that feeding a coarsely ground meal to pigs changed the physicochemical and microbial properties of the digesta and the adherence capacity of Salmonella (Mikkelsen, Naughton, Hedemann, \& Jensen, 2004).

Compared to other types of feed, liquid feed (such as whey) has been reported as a protective factor in some studies (Farzan et al., 2006; Lo Fo Wong et al., 2004; Poljak, Dewey, Friendship, Martin, \& Christensen, 2008) and alternatively, some studies demonstrated a higher risk for farms using dry feed (Beloeil et al., 2004; Von Altrock, Schutte, \& Hildebrandt, 2000). Farms using liquid feeding of by-products, such as whey, had a lower risk of a Salmonella infection than herds not using such a system. Herds that used a trough feeding system had a four times higher risk of a Salmonella infection than herds not using this feeding system (Van der Wolf et al., 1999). The lower pH might be the relevant protective factor in liquid feeding systems. Piggeries with liquid feeding and 
addition of whey had a 2.6-times lower odds ratio to be test seropositive than pigs not getting whey (Lo Fo Wong et al., 2004). Because whey is high in lactose, it could cause diarrhoea in animals with a low tolerance for lactose, although pigs are relatively lactose tolerant and if used at appropriate concentrations does not cause diarrhoea. Lactose stimulates the growth of certain bacteria in the intestinal tract of pigs, especially lactobacilli and an inverse correlation seems to exist between the fecal shedding of Salmonella and the fecal concentrations of lactobacilli (Wells, Yen, \& Miller, 2005). In recent years the use of oilseeds, especially soya, has been critically discussed. Tracing from a pig herd positive for $S$. Cubana discovered the origin in a Swedish feed plant from which 77 pig farms had received feed (Osterberg, Vagsholm, Boqvist, \& Lewerin, 2006). Soya was identified as major risk factor. Epidemiological studies showed that the use of fermented feed could significantly reduce Salmonella prevalence in pigs compared to the use of normal feed (Van der Wolf et al., 2001; Van Winsen et al., 2002).

\subsubsection{Other control measures}

The development of new genetic poultry lines to control measure of Campylobacter colonization in poultry for improved safety of poultry meat is only beginning. As there are two recently published comprehensive reviews on the genomics of genetic resistance to pathogenic microorganisms including Campylobacter (Calenge \& Beaumont, 2012; Swaggerty et al., 2009), this specific measure is not discussed in detail in this review.

\subsection{Control measures at secondary production}

In general, as with measures used to control pathogens in primary production, strategies aimed at controlling one pathogen in the processing environment often also apply to other bacteria. In the following, L. monocytogenes and Cronobacter are used as examples on how to control persistence at secondary production.

\subsubsection{Hygiene measures}

$L$. monocytogenes is ubiquitous in the environment and may therefore be transmitted into the processing facility by the raw material, the workers, tools, trucks etc, where it may or may not persist. This may cause problems of persistence within the processing facility causing re-contamination of food. The challenge for food manufacturers is thus to direct efforts to prevent the entry and establishment of L. monocytogenes within the processing environment. Good Manufacturing Practices (GMP) and employee training will facilitate this. In addition, an adequate Hazard Analysis Critical Control Plan (HACCP), or similar type plan, is necessary. The focus of such a plan should be on the production environment, the people and the facility, minimizing the opportunity for entry of contamination and spread of contamination within the production plant. One example is the introduction of L. monocytogenes and Enterobacteriaceae from operators moving between different zones. The production facilities and equipment should fulfil international regulations and standards for hygienic design, such as ISO (International Organization for Standardisation, 2002) and the EC regulation on food hygiene and machinery (European parliament, 2004, 2006), so that if contamination does enter the facility, there are limited opportunities for persistence. It is also very important to maintain equipment and protect production lines during any building work or reconstruction. Proper zoning is important to prevent contamination of the food produced with bacteria from the processing environment. Zoning starts with defining wet and dry zones and within these define levels of basic, medium and high hygiene zones. Dry zones should be kept dry to prevent growth of bacteria as these will not multiply in the absence of water. One example is that hand-washing creates an increase in the humidity in the dry zone environment and thus the need for hand washing facilities within or even in the air locks should be carefully evaluated.

\subsubsection{Limit the opportunities for contamination}

In order to limit the opportunities for contamination and persistence, cleaning routines of facilities and equipment should be designed to avoid selection of pathogenic bacteria with enhanced survival capacity. It is important to:

1. Prevent attachment: Some studies have shown that persistent bacteria may have a greater ability to attach to surfaces and form biofilm (Aase et al., 2000; Borucki et al., 2003; Lunden et al., 2000; Norwood \& Gilmour, 1999). It is not possible to identify one single material which is resistant to bacterial attachment and suitable for all purposes (Faille \& Carpentier, 2009). However, in comparative studies, stainless steel has been shown to be the material with lowest adherence of microorganisms or as easiest to clean (Midelet \& Carpentier, 2002; Rodriguez \& McLandsborough, 2007; Somers \& Wong, 2004). Persistence has been linked to use of porous materials (Mead \& Scott, 1994) and cleanability is therefore crucial when choosing materials. Porous materials should therefore be avoided.

2. Prevent possibilities of growth and biofilm formation. This can be achieved by use of antifouling or antibacterial materials in production facilities and using a cleaning routine with a short time between production and cleaning/disinfection. There are many materials that have incorporated bacteriostatic or bacteriocidal agents, e.g. silver containing AgION stainless steel (Campoccia, Montanaro, \& Arciola, 2013; Hasan, Crawford, \& Ivanova, 2013), or titanium nitride coating (Skovager et al., 2013). A common problem with these materials is neutralization of the antimicrobial component by proteins and therefore their efficacy in practical use can be limited (Chaitiemwong, Hazeleger, \& Beumer, 2010; Møretrø, Hoiby-Pettersen, Habimana, Heir, \& Langsrud, 2011; Rodrigues, Teixeira, Oliveira, \& Azeredo, 2011). Their use to eradicate or avoid persisters is therefore questionable. A better strategy is to avoid contamination in the first place.

3. Eliminate bacteria at critical sites. Microbial biofilms can be removed using regular cleaning agents based on chlorinated alkaline detergents and mechanical energy, although an additional cleaning step with an acid cleaner may be included on periodically to remove layers of inorganic salts that may protect bacteria (Stanga, 2010).

\subsubsection{Cleaning, disinfection and biofilm removal}

Disinfectants should meet efficacy criteria as determined in standardized tests both in suspension and on surfaces (CEN., 1997, 2002). Since biofilm can be managed by a cleaning process that disperses the cells, a prerequisite for disinfection should be effective cleaning that suspends biofilm cells. Several studies have been done to determine which types of disinfectants are most effective against biofilms. The results from these studies are contradictory, probably due to differences in the biofilms, methods and disinfectants tested (Belessi, Gounadaki, Psomas, \& Skandamis, 2011; Cruz \& Fletcher, 2012).

Bacteria resistant to several disinfectants have been isolated (Bore \& Langsrud, 2005), but in most cases, failure in disinfection is not due to resistance (Carpentier \& Cerf, 2011; Meyer, 2006). A robust disinfection routine should include alternation between chemical disinfectants with different properties and mechanisms of action, or between chemical and physical disinfection such as heat or UV.

The strategy that has contributed to the most dramatic reduction in Cronobacter spp. occurrence has been the concept of 'dry 
cleaning' being applied to the facility. Traditionally, wet cleaning, foaming with sanitizer and rinsing have been practiced. The concept of 'dry cleaning' is to keep dry zones dry. Thus, spray dryers, dry mixers, storage silos packaging machines should be dry cleaned. Vacuum cleaners are the most common tools for dry cleaning. For more information on cleaning strategies in dry food processing environments we refer to expert guidelines (Beuchat et al., 2011). This has led to lower levels of Cronobacter spp. in the environment, no risk from water contamination of the lines and increased product quality and consistency.

Alternative prevention strategies aiming at limiting the growth of $L$. monocytogenes and Cronobacter in foods and on surfaces include the use of bacteriophages as processing aids (Coffey, Mills, Coffey, McAuliffe, \& Ross, 2010; Endersen et al., 2014; Kim, Klumpp, \& Loessner, 2007; Mahony, McAuliffe, Ross, \& van Sinderen, 2011)

\subsubsection{Sampling to verify control}

Assuming compliance with HACCP or the HACCP-type protocol in use, an important tool in prevention of persistence within the facility is an appropriate sampling plan to verify such compliance. To make a meaningful sampling plan it is important to identify the critical sampling sites and the pathogens of concern. Thus, in monitoring the production environment by sampling for L. monocytogenes it is important to focus sampling to sites where occurrence of $L$. monocytogenes is expected and where contamination is likely to occur. In this regard, the European Union Reference Laboratory for $L$. monocytogenes has published guidelines for processing environment sampling (European Union Reference Laboratory for Listeria monocytogenes, 2012). Trend analysis of the results from such sampling should be undertaken, enabling a rapid response to changes that may indicate a potential loss of control and thus enable timely corrective actions. Because L. monocytogenes is ubiquitous, it is important to remember that finding a positive result should be viewed as a success of the monitoring program rather than a failure of hygiene measures. Being aware of the occurrence of $L$. monocytogenes in the processing environment is important as this occurrence can be dealt with. Having an action plan in the case of a positive result from sampling as part of the hygiene procedures is essential. In this way, food contamination can be avoided and food safety improved. Instead of sampling for the presence of specific pathogens, indicator microorganisms may be preferential given that it is possible to find a suitable indicators for the pathogen in the given processing environment.

In order to mitigate diseases caused by Cronobacter spp., the Food and Agricultural Organisation (FAO) and World Health Organisation (WHO) have developed a risk assessment model for Cronobacter species in powdered infant formula (FAO/WHO, 2008). This model can facilitate control measures aimed at reducing the occurrence of Cronobacter spp. in powdered infant formula, and it can be implemented along with specific microbiological criteria. It focuses on the elimination of batches of powdered infant formula that are deemed unacceptable (in accordance with the specified sampling plan), and estimates the risk reduction that can be obtained following removal of product that fails to meet the criteria. The model can also be used to assess the impact of sampling in terms of risk reduction through sampling alone, or in association with other risk reducing strategies such as preparation and storage strategies in the home. The model allows risk managers to explore the impact on relative risk and is freely available; interested food producers are encouraged to make use of this analytical tool.

\section{Future perspectives}

Despite the knowledge gained on persistence of foodborne pathogens, persistence is not fully understood. The exciting prospect afforded by new sequencing technologies has implications for future studies on the ecology and pathology of these pathogens. Such technologies enable the study of changes in the composition of microbial communities, including non-culturable microorganisms, over time and space and should lead to a better understanding of the mechanisms of persistence. Furthermore, community-analysis methodology and metagenomics will enable the acquisition of microbiomes to be analysed comprehensively, adding to the body of knowledge of persistence.

For E. coli $0157: \mathrm{H} 7$ there is an obvious lack of data on strain comparisons in super-shedders. The assumption is that persistent shedding is shedding of strains of the same genotype, but there is limited evidence for this. Additionally, there are limited studies on the time of persistent shedding or on the transfer of persistently shed strains to the animal hide then to the carcass during processing and to the final product. Understanding the mechanisms whereby animals show the characteristics of super-shedders are vital: it was demonstrated very elegantly by Matthews et al. (2006a) that targeting these animals specifically would have a very large effect on the incidence of $E$. coli 0157 infection.

More knowledge on the Listeria strains contaminating processing facilities and the genetic and physiological factors that allow persistence is needed. To obtain this, more relevant models simulating niches in the food production environments combined with analytical tools to investigate the composition as well as genetic and physiological responses of complex microbiota should be developed (Malley et al., 2013). This will provide more relevant background information needed to develop new eradication strategies. Examples of new principles for combating biofilms that could be further investigated include the use of bacteriophages, targeting cell-to-cell communication, or the iron pathway or enzymes attaching specific biofilm components or new antibacterial materials. With new and fast techniques for strain characterization, differentiation of $L$. monocytogenes strains with respect to virulence will be possible. Thus, virulence of a particular isolate may be taken into account in risk assessment.

With systematic studies, the current knowledge gaps on persistence of Salmonella at various levels of the farm-to-fork approach can be reduced. Therefore, molecular biological methods that allow fast strain characterization and differentiation of the pathogen in various matrices need to be improved. The aim should be to enhance the scientific understanding of the behaviour and persistence of Salmonella under the multi-faceted farm-to-fork environments of feed matrices, compound feed production, and farm level as well as the processing steps slaughtering, dissection, packaging, and transport.

The current knowledge of the virulence and epidemiology of Cronobacter spp. is limited. The virulence traits are uncertain, yet it is important to distinguish between pathogenic and nonpathogenic strains. Future research should focus on an improved understanding of the diversity of the genus in order to define its ecology, epidemiology, virulence and role in human infections. In addition, there should be a focus on the management of this increasingly important bacterium in the production environment. Publication of the genome of $C$. sakazakii BAA-894 (Kucerova et al., 2010) will contribute to these studies.

Despite intensive research over the last two decades, there is still no single effective measure that can be applied to prevent or to reduce colonization of broiler flocks by Campylobacter spp. Therefore, neither the prevalence of campylobacters in broiler flocks, nor contamination of broiler products at the retail level have been reduced in Europe in recent years. In fact, the trend in the number of poultry meat consumption-related human campylobacteriosis cases has increased over recent years (EFSA, 2013). There is still a need for fundamental and applied research with a focus on 
bacterial persistence that will lead to development of more effective measures for Campylobacter control in commercial poultry settings and therefore ensure consumer protection.

\section{Conclusions}

Whether at primary production or secondary processing of food, contamination by persistent foodborne pathogens is a risk to human health. This risk has been demonstrated for the major foodborne pathogens E. coli 0157:H7, Salmonella spp. L. monocytogenes, Cronobacter spp. and Campylobacter spp., all of which can persist. Understanding the mechanisms of persistence at the different levels in the farm to fork continuum is important in combating such persistence and by doing this improving food safety. Future concepts of prevention should not be based on the control of the production chain endpoint, but on process control throughout the chain.

\section{Acknowledgements}

This work was supported by the 7th Framework Programme projects FOODSEG (project number 266061) and PROMISE (project number 265877), and by the Danish Research Council for Strategic Research (project number 2101-08-0030; HI, MHL) and The Foundation for Research Levy on Agricultural Products in Norway (SL, TM (project number 224921/F40)).

\section{References}

Aase, B., Sundheim, G., Langsrud, S., \& Rorvik, L. M. (2000). Occurrence of and a possible mechanism for resistance to a quaternary ammonium compound in Listeria monocytogenes. International Journal of Food Microbiology, 62(1-2), 5763.

Abley, M. J., Wittum, T. E., Funk, J. A., \& Gebreyes, W. A. (2012). Antimicrobial susceptibility, pulsed-field gel electrophoresis, and multi-locus sequence typing of Campylobacter coli in swine before, during, and after the slaughter process. Foodborne Pathogens and Disease, 9(6), 506-512.

Alali, W. Q., Hofacre, C. L., Mathis, G. F., \& Faltys, G. (2013). Effect of essential oil compound on shedding and colonization of Salmonella enterica serovar Heidelberg in broilers. Poultry Science, 92(3), 836-841.

Alali, W. Q., Sargeant, J. M., Nagaraja, T. G., \& DeBey, B. M. (2004). Effect of antibiotics in milk replacer on fecal shedding of Escherichia coli 0157:H7 in calves. Journal of Animal Science, 82(7), 2148-2152.

Annous, B. A., Fratamico, P. M., \& Smith, J. L. (2009). Scientific status summary. Journal of Food Science, 74(1), 1750-3841.

Arthur, T. M., Bosilevac, J. M., Nou, X. W., Shackelford, S. D., Wheeler, T. L., Kent, M. P., et al. (2004). Escherichia coli 0157 prevalence and enumeration of aerobic bacteria, Enterobacteriaceae, and Escherichia coli 0157 at various steps in commercial beef processing plants. Journal of Food Protection, 67(4), 658-665.

Arku, B., Mullane, N., Fox, E., Fanning, S., \& Jordan, K. (2008). Enterobacter sakazakii survives spray drying. International Journal of Dairy Technology, 61(1), 102-108.

Bach, S. J., Selinger, L. J., Stanford, K., \& McAllister, T. A. (2005). Effect of supplementing corn- or barley-based feedlot diets with canola oil on faecal shedding of Escherichia coli 0157:H7 by steers. Journal of Applied Microbiology, 98(2), $464-475$.

Bagge-Ravn, D., Ng, Y., Hjelm, M., Christiansen, J. N., Johansen, C., \& Gram, L. (2003). The microbial ecology of processing equipment in different fish industries analysis of the microflora during processing and following cleaning and disinfection. International Journal of Food Microbiology, 87(3), 239-250.

Baird, B. E., Lucia, L. M., Acuff, G. R., Harris, K. B., \& Savell, J. W. (2006). Beef hide antimicrobial interventions as a means of reducing bacterial contamination. Meat Science, 73(2), 245-248.

Barker, J., Humphrey, T. J., \& Brown, M. W. R. (1999). Survival of Escherichia coli 0157 in a soil protozoan: implications for disease. FEMS Microbiology Letters, 173(2), $291-295$.

Barkocy-Gallagher, G. A., Arthur, T. M., Rivera-Betancourt, M., Nou, X. W., Shackelford, S. D., Wheeler, T. L., et al. (2003). Seasonal prevalence of Shiga toxin-producing Escherichia coli, including 0157:H7 and non-0157 serotypes, and Salmonella in commercial beef processing plants. Journal of Food Protection, 66(11), 1978-1986.

Baumgartner, A., Grand, M., Liniger, M., \& Iversen, C. (2009). Detection and frequency of Cronobacter spp. (Enterobacter sakazakii) in different categories of ready-to-eat foods other than infant formula. International Journal of Food Microbiology, 136(2), 189-192.

Belessi, C. E. A., Gounadaki, A. S., Psomas, A. N., \& Skandamis, P. N. (2011). Efficiency of different sanitation methods on Listeria monocytogenes biofilms formed under various environmental conditions. International Journal of Food Microbiology, 145, S46-S52.

Beloeil, P. A., Fravalo, P., Fablet, C., Jolly, J. P., Eveno, E., Hascoet, Y., et al. (2004). Risk factors for Salmonella enterica subsp enterica shedding by market-age pigs in French farrow-to-finish herds. Preventive Veterinary Medicine, 63(1-2), 103120.

Benchaar, C., Calsamiglia, S., Chaves, A. V., Fraser, G. R., Colombatto, D. McAllister, T. A., et al. (2008). A review of plant-derived essential oils in ruminant nutrition and production. Animal Feed Science and Technology, 145(14), 209-228.

Beuchat, L. R., Kim, H., Gurtler, J. B., Lin, L. C., Ryu, J. H., \& Richards, G. M. (2009) Cronobacter sakazakii in foods and factors affecting its survival, growth, and inactivation. International Journal of Food Microbiology, 136(2), 204-213.

Beuchat, L. R., Komitopoulou, E., Beckers, H., Betts, R. P., Bourdichon, F., Fanning, S. et al. (2013). Low-water activity foods: increased concern as vehicles of foodborne pathogens. Journal of Food Protection, 76(1), 150-172.

Beuchat, L. R., Komitopoulou, E., Betts, R., Beckers, H., Bourdichon, F., Joosten, H. et al. (2011). Persistence and survival of pathogens in dry foods and dry foods processing environments (pp. 1-48). ILSI Europe report series.

Binter, C., Straver, J. M., Haggblom, P., Bruggeman, G., Lindqvist, P. A., Zentek, J., et al (2011). Transmission and control of Salmonella in the pig feed chain: a conceptual model. International Journal of Food Microbiology, 145, S7-S17.

Bore, E., \& Langsrud, S. (2005). Characterization of micro-organisms isolated from dairy industry after cleaning and fogging disinfection with alkyl amine and peracetic acid. Journal of Applied Microbiology, 98(1), 96-105.

Borucki, M. K., Peppin, J. D., White, D., Loge, F., \& Call, D. R. (2003). Variation in biofilm formation among strains of Listeria monocytogenes. Applied and Environmental Microbiology, 69(12), 7336-7342.

Brashears, M. M., Galyean, M. L., Loneragan, G. H., Mann, J. E., \& Killinger-Mann, K. (2003a). Prevalence of Escherichia coli 0157:H7 and performance by beef feedlot cattle given Lactobacillus direct-fed microbials. Journal of Food Protection, 66(5) $748-754$

Brashears, M. M., Jaroni, D., \& Trimble, J. (2003b). Isolation, selection, and characterization of lactic acid bacteria for a competitive exclusion product to reduce shedding of Escherichia coli 0157:H7 in cattle. Journal of Food Protection, 66(3), 355-363.

Breeuwer, P., Lardeau, A., Peterz, M., \& Joosten, H. M. (2003). Desiccation and heat tolerance of Enterobacter sakazakii. Journal of Applied Microbiology, 95(5), $967-$ 973.

Bremer, P. J., Monk, I., \& Osborne, C. M. (2001). Survival of Listeria monocytogenes attached to stainless steel surfaces in the presence or absence of Flavobacterium spp. Journal of Food Protection, 64(9), 1369-1376.

Bridier, A., Briandet, R., Thomas, V., \& Dubois-Brissonnet, F. (2011). Comparative biocidal activity of peracetic acid, benzalkonium chloride and orthophthalaldehyde on 77 bacterial strains. The Journal of Hospital Infection, 78(3), 208-213.

Buckley, A. M., Wang, J., Hudson, D. L., Grant, A. J., Jones, M. A., Maskell, D. J., et al. (2010). Evaluation of live-attenuated Salmonella vaccines expressing Campylobacter antigens for control of C. jejuni in poultry. Vaccine, 28(4), 1094-1105.

Bui, X. T., Winding, A., Qvortrup, K., Wolff, A., Bang, D. D., \& Creuzenet, C. (2012) Survival of Campylobacter jejuni in co-culture with Acanthamoeba castellanii: role of amoeba-mediated depletion of dissolved oxygen. Environmental Microbiology, 14(8), 2034-2047.

Burrows, M. R., \& Rankin, J. D. (1970). A further examination of the survival of pathogenic bacteria in cattle slurry. British Veterinary Journal, 126(8), xxxiixxxiv.

Burt, S. A., \& Reinders, R. D. (2003). Antibacterial activity of selected plant essential oils against Escherichia coli 0157:H7. Letters in Applied Microbiology, 36(3), 162167.

Calenge, F., \& Beaumont, C. (2012). Toward integrative genomics study of genetic resistance to Salmonella and Campylobacter intestinal colonization in fowl. Frontiers in Genetics, 3(261), 14.

Campoccia, D., Montanaro, L., \& Arciola, C. R. (2013). A review of the biomaterials technologies for infection-resistant surfaces. Biomaterials, 34(34), 8533-8554.

Carlson, B. A., Nightingale, K. K., Mason, G. L., Ruby, J. R., Choat, W. T. Loneragan, G. H., et al. (2009). Escherichia coli 0157:H7 strains that persist in feedlot cattle are genetically related and demonstrate an enhanced ability to adhere to intestinal epithelial cells. Appl Environ Microbiol, 75(18), 5927-5937.

Carpentier, B., \& Cerf, O. (2011). Review - persistence of Listeria monocytogenes in food industry equipment and premises. International Journal of Food Microbiology, 145(1), 1-8.

Carvalho, C. M., Gannon, B. W., Halfhide, D. E., Santos, S. B., Hayes, C. M., Roe, J. M. et al. (2010). The in vivo efficacy of two administration routes of a phage cocktail to reduce numbers of Campylobacter coli and Campylobacter jejuni in chickens. BMC Microbiology, 10, 232.

Casey, P. G., Gardiner, G. E., Casey, G., Bradshaw, B., Lawlor, P. G., Lynch, P. B., et al. (2007). A five-strain probiotic combination reduces pathogen shedding and alleviates disease signs in pigs challenged with Salmonella enterica serovar Typhimurium. Applied and Environmental Microbiology, 73(6), 1858-1863.

CEN. (1997). EN 1276. Chemical disinfectants and antiseptics - quantitative suspension test for the evaluation of bactericidal activity of chemical disinfectants and antiseptics for use in food, industrial, domestic and institutional areas - test methods and requirements (phase 2-step 1 ).

CEN. (2002). EN 13697. Chemical disinfectants and antiseptics - quantitative nonporous surface test for the evaluation of bactericidal and/or fungicidal activity of 
chemical disinfectants and antiseptics for use in food, industrial, domestic and institutional areas - test methods and requirements (phase 2-step 2).

Chaitiemwong, N., Hazeleger, W. C., \& Beumer, R. R. (2010). Survival of Listeria monocytogenes on a conveyor belt material with or without antimicrobial additives. International Journal of Food Microbiology, 142(1-2), 260-263.

Chapman, P. A. (2000). Sources of Escherichia coli 0157 and experiences over the past 15 years in Sheffield, UK. Journal of Applied Microbiology, 88, 51S-60S.

Chase-Topping, M., Gally, D., Low, C., Matthews, L., \& Woolhouse, M. (2008) Super-shedding and the link between human infection and livestock carriage of Escherichia coli 0157. Nature Reviews in Microbiology, 6(12), 904912.

Chen, M., \& Wolin, M. J. (1979). Effect of monensin and lasalocid-sodium on the growth of methanogenic and rumen saccharolytic bacteria. Applied and Environmental Microbiology, 38(1), 72-77.

Clark, J. D., Oakes, R. D., Redhead, K., Crouch, C. F., Francis, M. J., Tomley, F. M., et al. (2012). Eimeria species parasites as novel vaccine delivery vectors: antiCampylobacter jejuni protective immunity induced by Eimeria tenella-delivered CjaA. Vaccine, 30(16), 2683-2688.

Coffey, B., Mills, S., Coffey, A., McAuliffe, O., \& Ross, R. P. (2010). Phage and their lysins as biocontrol agents for food safety applications. Annual Review of Food Science and Technology, 1, 449-468.

Coffey, B., Rivas, L., Duffy, G., Coffey, A., Ross, R. P., \& McAuliffe, O. (2011). Assessment of Escherichia coli 0157:H7-specific bacteriophages e11/2 and e4/1c in model broth and hide environments. International Journal of Food Microbiology, 147(3), $188-194$.

Cote, C., \& Quessy, S. (2005). Persistence of Escherichia coli and Salmonella in surface soil following application of liquid hog manure for production of pickling cucumbers. Journal of Food Protection, 68(5), 900-905.

Cruz, C. D., \& Fletcher, G. C. (2012). Assessing manufacturers' recommended concentrations of commercial sanitizers on inactivation of Listeria monocytogenes. Food Control, 26(1), 194-199.

D'Aoust, J. Y. (1977). Salmonella and chocolate industry - review. Journal of Food Protection, 40(10), 718-727.

D’Aoust, J. Y., \& Sewell, A. M. (1986). Slow rehydration for detection of Salmonella spp in feeds and feed ingredients. Appl Environ Microbiol, 51(6), 1220-1223.

Damjanova, I., Jakab, M., Farkas, T., Meszaros, J., Galantai, Z., Turcsanyi, I., et al. (2011). From farm to fork follow-up of thermotolerant campylobacters throughout the broiler production chain and in human cases in a Hungarian county during a ten-months period. International Journal of Food Microbiology, $150(2-3)$, 95-102.

Dancer, G. I., Mah, J. H., Rhee, M. S., Hwang, I. G., \& Kang, D. H. (2009). Resistance of Enterobacter sakazakii (Cronobacter spp.) to environmental stresses. Journal of Applied Microbiology, 107(5), 1606-1614.

Daniels, M. J., Hutchings, M. R., \& Greig, A. (2003). The risk of disease transmission to livestock posed by contamination of farm stored feed by wildlife excreta. Epidemiology and Infection, 130(3), 561-568.

Davies, R. H., \& Wray, C. (1997). Distribution of Salmonella contamination in ten animal feedmills. Veterinary Microbiology, 57(2-3), 159-169.

Davis, M. A., Rice, D. H., Sheng, H., Hancock, D. D., Besser, T. E., Cobbold, R., et al (2006). Comparison of cultures from rectoanal-junction mucosal swabs and feces for detection of Escherichia coli 0157 in dairy heifers. Applied and Environmental Microbiology, 72(5), 3766-3770.

De Busser, E. V., De Zutter, L., Dewulf, J., Houf, K., \& Maes, D. (2013). Salmonella control in live pigs and at slaughter. Veterinary Journal, 196(1), 20-27.

Dennis, I., \& Blanchard, P. (2004). Effect of feeding potassium diformate on incidence of Salmonella infection on a commercial unit. Pig Journal, 54, 157-160.

Deschepper, K., Bruggeman, G., \& Molly, K. (2005). Aromabiotic: the ultimate hurdle against Salmonella. World Poultry, 21(Special), 12-13.

Desin, T. S., Koster, W., \& Potter, A. A. (2013). Salmonella vaccines in poultry: past, present and future. Expert Review of Vaccines, 12(1), 87-96.

Djordjevic, D., Wiedmann, M., \& McLandsborough, L. A. (2002). Microtiter plate assay for assessment of Listeria monocytogenes biofilm formation. Applied and Environmental Microbiology, 68(6), 2950-2958.

Doyscher, D., Fieseler, L., Dons, L., Loessner, M. J., \& Schuppler, M. (2013). Acanthamoeba feature a unique backpacking strategy to trap and feed on Listeria monocytogenes and other motile bacteria. Environmental Microbiology, 15(2), 433-446.

Duncan, S. H., Leitch, E. C. M. Stanley, K. N., Richardson, A. J., Laven, R. A., Flint, H. J. et al. (2004). Effects of esculin and esculetin on the survival of Escherichia coli 0157 in human faecal slurries, continuous-flow simulations of the rumen and colon and in calves. British Journal of Nutrition, 91(5), 749-755.

Eberle, K. N., \& Kiess, A. S. (2012). Phenotypic and genotypic methods for typing Campylobacter jejuni and Campylobacter coli in poultry. Poultry Science, 91(1) $255-264$.

Edelson-Mammel, S. G., Porteous, M. K., \& Buchanan, R. L. (2005). Survival of Enterobacter sakazakii in a dehydrated powdered infant formula. Journal of Food Protection, 68(9), 1900-1902.

Edrington, T. S., Callaway, T. R., Ives, S. E., Engler, M. J., Looper, M. L., Anderson, R. C., et al. (2006). Seasonal shedding of Escherichia coli 0157:H7 in ruminants: a new hypothesis. Foodborne Pathogens and Disease, 3(4), 413-421.

Edrington, T. S., Callaway, T. R., Varey, P. D., Jung, Y. S., Bischoff, K. M., Elder, R. O. et al. (2003). Effects of the antibiotic ionophores monensin, lasalocid, laidlomycin propionate and bambermycin on Salmonella and E. coli 0157:H7 in vitro. Journal of Applied Microbiology, 94(2), 207-213.
EFSA. (2007). The community summary report on trends and sources of zoonoses, zoonotic agents, antimicrobial resistance and foodborne outbreaks in the European Union in 2006. EFSA Journal, 130, 1.

EFSA. (2008a). Microbiological risk assessment in feedingstuffs for food-producing animals - scientific opinion of the panel on biological hazards. EFSA Journal, $720,1-84$.

EFSA. (2008b). Scientific opinion of the panel on biological hazards on a request from the health and consumer protection, directorate general, European Commission on microbiological risk assessment in feedingstuffs for foodproducing animals. EFSA Journal, 720, 1-84.

EFSA. (2012). The European Union summary report on trends and sources of zoonoses, zoonotic agents and food-borne outbreaks in the European Union in 2010. EFSA Journal, 10, 2597.

EFSA. (2013). The European Union summary report on trends and sources of zoonoses, zoonotic agents and food-borne outbreaks in 2011. EFSA Journal, 11(4), 3129.

El-Shibiny, A., Scott, A., Timms, A., Metawea, Y., Connerton, P., \& Connerton, I. (2009). Application of a group II Campylobacter bacteriophage to reduce strains of Campylobacter jejuni and Campylobacter coli colonizing broiler chickens. Journal of Food Protection, 72(4), 733-740.

Elder, R. O., Keen, J. E., Siragusa, G. R., Barkocy-Gallagher, G. A., Koohmaraie, M., \& Laegreid, W. W. (2000). Correlation of enterohemorrhagic Escherichia coli 0157 prevalence in feces, hides, and carcasses of beef cattle during processing. Proceedings of the National Academy of Sciences of the United States of America, 97(7), 2999-3003.

Elhanafi, D., Dutta, V., \& Kathariou, S. (2010). Genetic characterization of plasmidassociated benzalkonium chloride resistance determinants in a Listeria monocytogenes strain from the 1998-1999 outbreak. Applied and Environmental Microbiology, 76(24), 8231-8238.

Endersen, L., O’Mahony, J., Hill, C., Ross, R. P., McAuliffe, O., \& Coffey, A. (2014). Phage therapy in the food industry. Annual Review of Food Science and Technology, 5, 327-349.

European Parliament. (2004). Regulation (EC) No 852/2004 of the European Parliament and of the Council of 29 April 2004 on the hygiene of foodstuffs.

European Parliament. (2006). Directive 2006/42/EC of the European Parliament and of the Council of 17 May 2006 on machinery, and amending Directive 95/16/EC (recast).

European Union Reference Laboratory for Listeria monocytogenes. (2012). Guidelines on sampling the food processing area and equipment for the detection of Listeria monocytogenes. In (Vol. 2013). Accessed June 2013.

Faille, C., \& Carpentier, B. (2009). Food contact surfaces, surface soiling and biofilm formation. In P. M. Fratamico, B. A. Annous, \& N. W. Gunther (Eds.), Biofilms in the food and beverage industries (pp. 304-330). Oxford, Cambridge, New Delhi: Woodhead Publishing Limited.

FAO/WHO. (2008). Risk assessment for Cronobacter sakazakii in powdered infant formula Accessed September 2012 http://www.fstools.org/ESAK/Home.aspx.

Farzan, A., Friendship, R. M., Dewey, C. E., Warriner, K., Poppe, C., \& Klotins, K. (2006). Prevalence of Salmonella spp. on Canadian pig farms using liquid or dryfeeding. Preventive Veterinary Medicine, 73(4), 241-254.

Ferreira, V., Wiedmann, M., Teixeira, P., \& Stasiewicz, M. J. (2014). Listeria monocytogenes persistence in food-associated environments: epidemiology, strain characteristics, and implications for public health. Journal of Food Protection, $77(1), 150-170$.

Fox, E. M., O'Mahony, T., Clancy, M., Dempsey, R., O’Brien, M., \& Jordan, K. (2009). Listeria monocytogenes in the Irish dairy farm environment. Journal of Food Protection, 72(7), 1450-1456.

Fox, E. M., Leonard, N., \& Jordan, K. (2011a). Molecular diversity of Listeria monocytogenes isolated from Irish dairy farms. Foodborne Pathogens and Disease, 8(5), 635-641.

Fox, E. M., Leonard, N., \& Jordan, K. (2011b). Physiological and transcriptional characterization of persistent and nonpersistent Listeria monocytogenes isolates. Applied and Environmental Microbiology, 77(18), 6559-6569.

Franz, E., Semenov, A. V., Termorshuizen, A. J., de Vos, O. J., Bokhorst, J. G., \& van Bruggen, A. H. C. (2008). Manure-amended soil characteristics affecting the survival of E. coli 0157:H7 in 36 Dutch soils. Environmental Microbiology, 10(2), 313-327.

Fukushima, H., \& Seki, R. (2004). High numbers of Shiga toxin-producing Escherichia coli found in bovine faeces collected at slaughter in Japan. FEMS Microbiology Letters, 238(1), 189-197.

Giovannacci, I., Ragimbeau, C., Queguiner, S., Salvat, G., Vendeuvre, J. L. Carlier, V., et al. (1999). Listeria monocytogenes in pork slaughtering and cutting plants use of RAPD, PFGE and PCR-REA for tracing and molecular epidemiology. International Journal of Food Microbiology, 53(2-3), 127140.

González-Fandos, E., Sanz, J., García-Fernández, M. C., \& García-Arias, M. T. (2005). Effectiveness of disinfectants used in the food industry on microorganisms of sanitary interest. Acta Alimentaria, 34(3), 253-258.

González, M., \& Hänninen, M. L. (2012). Effect of temperature and antimicrobial resistance on survival of Campylobacter jejuni in well water: application of the Weibull model. Journal of Applied Microbiology, 113(2), 284-293.

Greub, G., \& Raoult, D. (2004). Microorganisms resistant to free-living amoebae. Clinical Microbiology Reviews, 17(2), 413-433.

Grim, C. J., Kotewicz, M. L., Power, K. A., Gopinath, G., Franco, A. A., Jarvis, K. G., et al. (2013). Pan-genome analysis of the emerging foodborne pathogen Cronobacter spp. suggests a species-level bidirectional divergence driven by niche adaptation. BMC Genomics, 14, 366 
Grönholm, L., Wirtanen, G., Ahlgren, K., Nordström, K., \& Sjöberg, A. M. (1999). Screening of antimicrobial activities of disinfectants and cleaning agents against foodborne spoilage microbes. Zeitschrift für Lebensmitteluntersuchung und Forschung A, 208(4), 289-298.

Gurtler, J. B., \& Beuchat, L. R. (2007a). Growth of Enterobacter sakazakii in reconstituted infant formula as affected by composition and temperature. Journal of Food Protection, 70(9), 2095-2103.

Gurtler, J. B., \& Beuchat, L. R. (2007b). Survival of Enterobacter sakazakii in powdered infant formula as affected by composition, water activity, and temperature. Journal of Food Protection, 70(7), 1579-1586.

Habib, I., Miller, W. G., Uyttendaele, M., Houf, K., \& De Zutter, L. (2009). Clonal population structure and antimicrobial resistance of Campylobacter jejuni in chicken meat from Belgium. Appl Environ Microbiol, 75(13), 4264-4272.

Habib, I., Uyttendaele, M., \& De Zutter, L. (2010). Survival of poultry-derived Campylobacter jejuni of multilocus sequence type clonal complexes 21 and 45 under freeze, chill, oxidative, acid and heat stresses. Food Microbiology, 27(6), 829-834.

Hakkinen, M., \& Schneitz, C. (1999). Efficacy of a commercial competitive exclusion product against Campylobacter jejuni. British Poultry Science, 40(5), 619-621.

Hald, B., Sommer, H. M., \& Skovgaard, H. (2007). Use of fly screens to reduce Campylobacter spp. introduction in broiler houses. Emerging Infectious Diseases, 13(12), 1951-1953.

Hancock, D. D., Besser, T. E., Rice, D. H., Herriott, D. E., \& Tarr, P. I. (1997). A longitudinal study of Escherichia coli $\mathrm{O} 157$ in fourteen cattle herds. Epidemiology and Infection, 118(2), 193-195.

Hasan, J., Crawford, R. J., \& Ivanova, E. P. (2013). Antibacterial surfaces: the quest for a new generation of biomaterials. Trends in Biotechnology, 31(5), 295-304.

Hastings, R., Colles, F. M., McCarthy, N. D., Maiden, M. C. J., \& Sheppard, S. K. (2011). Campylobacter genotypes from poultry transportation crates indicate a source of contamination and transmission. Journal of Applied Microbiology, 110(1), 266276.

Healy, B., Cooney, S., O’Brien, S., Iversen, C., Whyte, P., Nally, J., et al. (2010). Cronobacter (Enterobacter sakazakii): an opportunistic foodborne pathogen. Foodborne Pathogens and Disease, 7(4), 339-350.

Hein, I., Gadzov, B., Schoder, D., Foissy, H., Malorny, B., \& Wagner, M. (2009). Temporal and spatial distribution of Cronobacter isolates in a milk powder processing plant determined by pulsed-field gel electrophoresis. Foodborne Pathogens and Disease, 6(2), 225-233.

Heres, L., Engel, B., Urlings, H. A., Wagenaar, J. A., \& van Knapen, F. (2004). Effect of acidified feed on susceptibility of broiler chickens to intestinal infection by Campylobacter and Salmonella. Veterinary Microbiology, 99(34), 259-267.

Hermans, D., Van Deun, K., Messens, W., Martel, A., Van Immerseel, F., Haesebrouck, F., et al. (2011). Campylobacter control in poultry by current intervention measures ineffective: urgent need for intensified fundamental research. Veterinary Microbiology, 152(3-4), 219-228.

Himelright, I., Harris, E., Lorch, V., Anderson, M., Jones, T., Craig, A., et al. (2002). Enterobacter sakazakii infections associated with the use of powdered infant formula - Tennessee, 2001 (reprinted from MMWR, vol. 51, pg 297-300, 2002). Journal of the American Medical Association, 287(17), 2204-2205.

Holah, J. T., Bird, J., \& Hall, K. E. (2004). The microbial ecology of high-risk, chilled food factories; evidence for persistent Listeria spp. and Escherichia coli strains. Journal of Applied Microbiology, 97(1), 68-77.

Holah, J. T., \& Gibson, H. (2000). Biofilms: recent advances in their study and control. In L. V. Evans (Ed.), Food industry biofilms (pp. 211-235). Amsterdam, The Netherlands: Harwood Academic Publishers.

Holah, J. T., Taylor, J. H., Dawson, D. J., \& Hall, K. E. (2002). Biocide use in the food industry and the disinfectant resistance of persistent strains of Listeria monocytogenes and Escherichia coli. Journal of Applied Microbiology, 92, 111S-120S.

Hunter, C. J., \& Bean, J. F. (2013). Cronobacter: an emerging opportunistic pathogen associated with neonatal meningitis, sepsis and necrotizing enterocolitis. Journal of Perinatology, 33(8), 581-585.

Ica, T., Caner, V., Istanbullu, O., Nguyen, H. D., Ahmed, B., Call, D. R., et al. (2012). Characterization of mono- and mixed-culture Campylobacter jejuni biofilms. Applied and Environmental Microbiology, 78(4), 1033-1038.

International Organization for Standardisation. (2002). ISO 14159 Safety of machinery - hygiene requirements for the design of machinery.

Iversen, C., Lane, M., \& Forsythe, S. J. (2004). The growth profile, thermotolerance and biofilm formation of Enterobacter sakazakii grown in infant formula milk. Letters in Applied Microbiology, 38(5), 378-382.

Jacob, M. E., Paddock, Z. D., Renter, D. G., Lechtenberg, K. F., \& Nagaraja, T. G. (2010). Inclusion of dried or wet distillers' grains at different levels in diets of feedlot cattle affects fecal shedding of Escherichia coli 0157:H7. Applied and Environmental Microbiology, 76(21), 7238-7242.

Jagusztyn-Krynicka, E. K., Laniewski, P., \& Wyszynska, A. (2009). Update on Campylobacter jejuni vaccine development for preventing human campylobacteriosis. Expert Review of Vaccines, 8(5), 625-645.

Jensen, A. N., Dalsgaard, A., Baggesen, D. L., \& Nielsen, E. M. (2006). The occurrence and characterization of Campylobacter jejuni and C. coli in organic pigs and their outdoor environment. Veterinary Microbiology, 116(1-3), 96-105.

Jeong, D. K., \& Frank, J. F. (1994). Growth of Listeria monocytogenes at $10^{\circ} \mathrm{C}$ in biofilms with microorganisms isolated from meat and dairy processing environments. Journal of Food Protection, 57(7), 576-586.

Jones, P. W. (1976). The effect of temperature, solids content and pH on the survival of salmonellas in cattle slurry. British Veterinary Journal, 132(3), 284-293.
Joseph, S., Desai, P., Ji, Y., Cummings, C. A., Shih, R., Degoricija, L., et al. (2012) Comparative analysis of genome sequences covering the seven cronobacter species. Plos One, 7(11), e49455.

Kamphues, J., Papenbrock, S., Visscher, C., Offenberg, S., Neu, M., Verspohl, J., et al. (2007). Effects of feeds and feeding on Salmonella prevalence in pigs. Ubersichten zur Tierernahrung, 35(2), 233-279.

Kandhai, M. C., Reij, M. W., Gorris, L. G. M., Guillaume-Gentil, O., \& van Schothorst, M. (2004). Occurrence of Enterobacter sakazakii in food production environments and households. Lancet, 363(9402), 39-40.

Kastbjerg, V. G., \& Gram, L. (2009). Model systems allowing quantification of sensitivity to disinfectants and comparison of disinfectant susceptibility of persistent and presumed nonpersistent Listeria monocytogenes. Journal of Applied Microbiology, 106(5), 1667-1681.

Kastbjerg, V. G., \& Gram, L. (2012). Industrial disinfectants do not select for resistance in Listeria monocytogenes following long term exposure. International Journal of Food Microbiology, 160(1), 11-15.

Kempf, B., \& Bremer, E. (1998). Uptake and synthesis of compatible solutes as microbial stress responses to high-osmolality environments. Archives of Microbiology, 170(5), 319-330.

Khelef, N., Lecuit, M., Buchrieser, C., Cabanes, D., Dussurget, O., \& Cossart, P. (2006). Listeria monocytogenes and the genus Listeria. In M. Dworkin, S. Falkow, E. Rosenberg, K.-H. Schleifer, \& E. Stackebrandt (Eds.), The Prokaryotes (Vol. 4); (pp. 404-476). New York: Springer.

Kim, K. P., Klumpp, J., \& Loessner, M. J. (2007). Enterobacter sakazakii bacteriophages can prevent bacterial growth in reconstituted infant formula. International Journal of Food Microbiology, 115(2), 195-203.

Klancnik, A., Guzej, B., Jamnik, P., Vuckovic, D., Abram, M., \& Smole Možina, S. (2009). Stress response and pathogenic potential of Campylobacter jejuni cells exposed to starvation. Research in Microbiology, 160(5), 345-352.

Klancnik, A., Vuckovic, D., Plankl, M., Abram, M., \& Smole Možina, S. (2013). In vivo modulation of Campylobacter jejuni virulence in response to environmental stress. Foodborne Pathogens and Disease, 2, 2.

Kucerova, E., Clifton, S. W., Xia, X. Q., Long, F., Porwollik, S., Fulton, L., et al. (2010). Genome sequence of Cronobacter sakazakii BAA-894 and comparative genomic hybridization analysis with other Cronobacter species. Plos One, 5(3), A51-A60.

Kudva, I. T., Hatfield, P. G., \& Hovde, C. J. (1995). Effect of diet on the shedding of Escherichia coli 0157:H7 in a sheep model. Applied and Environmental Microbiology, 61(4), 1363-1370.

Kudva, I. T., Jelacic, S., Tarr, P. I., Youderian, P., \& Hovde, C. J. (1999). Biocontrol of Escherichia coli 0157 with 0157 -specific bacteriophages. Applied and Environmental Microbiology, 65(9), 3767-3773.

Lai, K. K. (2001). Enterobacter sakazakii infections among neonates, infants, children, and adults - case reports and a review of the literature. Medicine, 80(2), 113122.

Laisney, M. J., Gillard, M. O., \& Salvat, G. (2004). Influence of bird strain on competitive exclusion of Campylobacter jejuni in young chicks. British Poultry Science, 45(1), 49-54.

Latorre, A. A., Van Kessel, J. A. S., Karns, J. S., Zurakowski, M. J., Pradhan, A. K. Boor, K. J., et al. (2011). Increased in vitro adherence and on-farm persistence of predominant and persistent Listeria monocytogenes strains in the milking system. Applied and Environmental Microbiology, 77(11), 3676-3684.

Latorre, A. A., Van Kessel, J. A. S., Karns, J. S., Zurakowski, M. J., Pradhan, A. K. Zadoks, R. N., et al. (2009). Molecular ecology of Listeria monocytogenes: evidence for a reservoir in milking equipment on a dairy farm. Applied and Environmental Microbiology, 75(5), 1315-1323.

Lawrence, L. M., \& Gilmour, A. (1995). Characterization of Listeria monocytogenes isolated from poultry products and from the poultry processing environment by random amplification of polymorphic DNA and multilocus enzyme electrophoresis. Applied and Environmental Microbiology, 61(6), 2139-2144.

Layton, S. L., Morgan, M. J., Cole, K., Kwon, Y. M., Donoghue, D. J., Hargis, B. M., et al (2011). Evaluation of Salmonella-vectored Campylobacter peptide epitopes for reduction of Campylobacter jejuni in broiler chickens. Clinical and Vaccine Immunology, 18(3), 449-454.

Lienau, J. A., Ellerbroek, L., \& Klein, G. (2007). Tracing flock-related Campylobacter clones from broiler farms through slaughter to retail products by pulsed-field gel electrophoresis. Journal of Food Protection, 70(3), 536-542.

Ligowska, M., Cohn, M. T., Stabler, R. A., Wren, B. W., \& Brondsted, L. (2011). Effect of chicken meat environment on gene expression of Campylobacter jejuni and its relevance to survival in food. International Journal of Food Microbiology, 145 S111-S115.

Lim, J. Y., Li, J., Sheng, H., Besser, T. E., Potter, K., \& Hovde, C. J. (2007). Escherichia coli 0157:H7 colonization at the rectoanal junction of long-duration culture-positive cattle. Applied and Environmental Microbiology, 73(4), 1380-1382.

Lin, J. (2009). Novel approaches for Campylobacter control in poultry. Foodborne Pathogens and Disease, 6(7), 755-765.

Lin, L. C., \& Beuchat, L. R. (2007a). Survival and growth of Enterobacter sakazakii in infant cereal as affected by composition, reconstitution liquid, and storage temperature. Journal of Food Protection, 70(6), 1410-1422.

Lin, L. C., \& Beuchat, L. R. (2007b). Survival of Enterobacter sakazakii in infant cereal as affected by composition, water activity, and temperature. Food Microbiology, 24(7-8), 767-777.

Lo Fo Wong, D. M., Dahl, J., Stege, H., van der Wolf, P. J., Leontides, L., von Altrock, A., et al. (2004a). Herd-level risk factors for subclinical Salmonella infection in European finishing-pig herds. Preventive Veterinary Medicine, 62(4), 253-266. 
Lo Fo Wong, D. M., Dahl, J., Wingstrand, A., van der Wolf, P. J., von Altrock, A., \& Thorberg, B. M. (2004b). A European longitudinal study in Salmonella seronegative- and seropositive-classified finishing pig herds. Epidemiology and Infection, 132(5), 903-914.

Loc Carrillo, C., Atterbury, R. J., el-Shibiny, A., Connerton, P. L., Dillon, E., Scott, A., et al. (2005). Bacteriophage therapy to reduce Campylobacter jejuni colonization of broiler chickens. Applied and Environmental Microbiology, 71(11), 6554-6563.

Lomonaco, S., Decastelli, L., Nucera, D., Gallina, S., Bianchi, D. M., \& Civera, T. (2009) Listeria monocytogenes in Gorgonzola: subtypes, diversity and persistence over time. International Journal of Food Microbiology, 128(3), 516-520.

Luangtongkum, T., Jeon, B., Han, J., Plummer, P., Logue, C. M., \& Zhang, Q. J. (2009). Antibiotic resistance in Campylobacter: emergence, transmission and persistence. Future Microbiology, 4(2), 189-200.

Lunden, J., Autio, T., Markkula, A., Hellstrom, S., \& Korkeala, H. (2003). Adaptive and cross-adaptive responses of persistent and non-persistent Listeria monocytogenes strains to disinfectants. International Journal of Food Microbiology 82(3), 265-272.

Lunden, J. M., Miettinen, M. K., Autio, T. J., \& Korkeala, H. J. (2000). Persistent Listeria monocytogenes strains show enhanced adherence to food contact surface after short contact times. Journal of Food Protection, 63(9), 1204-1207.

Ly, T. M. C., \& Muller, H. E. (1990). Ingested Listeria monocytogenes survive and multiply in protozoa. Journal of Medical Microbiology, 33(1), 51-54.

Ma, J. C., Ibekwe, A. M., Yi, X., Wang, H. Z., Yamazaki, A., Crowley, D. E., et al. (2011). Persistence of Escherichia coli 0157:H7 and its mutants in soils. Plos One, 6(8), e23191.

Maciorowski, K. G., Herrera, P., Jones, F. T., Pillai, S. D., \& Ricke, S. C. (2007). Effects on poultry and livestock of feed contamination with bacteria and fungi. Animal Feed Science and Technology, 133(1-2), 109-136.

Mahony, J., McAuliffe, O., Ross, R. P., \& van Sinderen, D. (2011). Bacteriophages as biocontrol agents of food pathogens. Current Opinion in Biotechnology, 22(2), $157-163$.

Malley, T. J., Stasiewicz, M. J., Grohn, Y. T., Roof, S., Warchocki, S., Nightingale, K., et al. (2013). Implementation of statistical tools to support identification and management of persistent Listeria monocytogenes contamination in smoked fish processing plants. Journal of Food Protection, 76(5), 796-811.

Marouani-Gadri, N., Augier, G., \& Carpentier, B. (2009). Characterization of bacterial strains isolated from a beef-processing plant following cleaning and disinfection - influence of isolated strains on biofilm formation by Sakai and EDL 933 E. coli O157:H7. International Journal of Food Microbiology, 133(1-2), 62-67.

Matthews, L., Low, J. C., Gally, D. L., Pearce, M. C., Mellor, D. J., Heesterbeek, J. A. P., et al. (2006a). Heterogeneous shedding of Escherichia coli 0157 in cattle and its implications for control. Proceedings of the National Academy of Sciences of the United States of America, 103(3), 547-552.

Matthews, L., McKendrick, I. J., Ternent, H., Gunn, G. J., Synge, B., \& Woolhouse, M. E. J. (2006b). Super-shedding cattle and the transmission dynamics of Escherichia coli 0157. Epidemiology and Infection, 134(1), 131-142.

Mavri, A., Kurincic, M., \& Smole Mozina, S. (2012). The prevalence of antibiotic and biocide resistance among Campylobacter coli and Campylobacter jejuni from different sources. Food Technology and Biotechnology, 50(3), 371-376.

Mavri, A., \& Smole Možina, S. (2012). Involvement of efflux mechanisms in biocide resistance of Campylobacter jejuni and Campylobacter coli. Journal of Medical Microbiology, 61(6), 800-808.

McNeilly, T. N., Naylor, S. W., Mahajan, A., Mitchell, M. C., McAteer, S., Deane, D., et al. (2008). Escherichia coli O157:H7 colonization in cattle following systemic and mucosal immunization with purified H7 flagellin. Infection and Immunity, 76(6), 2594-2602.

Mead, G. C., \& Scott, M. J. (1994). Coagulase-negative staphylococci and coliform bacteria associated with mechanical defeathering of poultry carcasses. Letters in Applied Microbiology, 18(1), 62-64.

Melero, B., Juntunen, P., Hanninen, M. L., Jaime, I., \& Rovira, J. (2012). Tracing Campylobacter jejuni strains along the poultry meat production chain from farm to retail by pulsed-field gel electrophoresis, and the antimicrobial resistance of isolates. Food Microbiology, 32(1), 124-128.

Meyer, B. (2006). Does microbial resistance to biocides create a hazard to food hygiene? International Journal of Food Microbiology, 112(3), 275-279.

Midelet, G., \& Carpentier, B. (2002). Transfer of microorganisms, including Listeria monocytogenes, from various materials to beef. Appl Environ Microbiol, 68(8), 4015-4024.

Mikkelsen, L. L., Naughton, P. J., Hedemann, M. S., \& Jensen, B. B. (2004). Effects of physical properties of feed on microbial ecology and survival of Salmonella enterica serovar Typhimurium in the pig gastrointestinal tract. Appl Environ Microbiol, 70(6), 3485-3492.

Miettinen, M. K., Bjorkroth, K. J., \& Korkeala, H. J. (1999). Characterization of Listeria monocytogenes from an ice cream plant by serotyping and pulsed-field gel electrophoresis. International Journal of Food Microbiology, 46(3), 187-192.

Mitscherlich, E., \& Marth, E. H. (1984). Microbial survival in the environment: bacteria and rickettsiae important in human and animal health. Berlin: Springer-Verlag.

MMWR. (1989). Listeriosis associated with consumption of turkey franks. Morbidity and Mortality Weekly Report, 38(15), 267-268.

Molloy, C., Cagney, C., O’Brien, S., Iversen, C., Fanning, S., \& Duffy, G. (2009). Surveillance and characterisation by pulsed-field gel electrophoresis of Cronobacter spp. in farming and domestic environments, food production animals and retail foods. International Journal of Food Microbiology, 136(2), 198-203.
Møretrø, T., Hoiby-Pettersen, G. S., Habimana, O., Heir, E., \& Langsrud, S. (2011). Assessment of the antibacterial activity of a triclosan-containing cutting board. International Journal of Food Microbiology, 146(2), 157-162.

Møretrø, T., Midtgaard, E. S., Nesse, L. L., \& Langsrud, S. (2003). Susceptibility of Salmonella isolated from fish feed factories to disinfectants and air-drying at surfaces. Veterinary Microbiology, 94(3), 207-217.

Mubiru, D. N., Coyne, M. S., \& Grove, J. H. (2000). Mortality of Escherichia coli 0157 : $\mathrm{H7}$ in two soils with different physical and chemical properties. Journal of Environmental Quality, 29(6), 1821-1825.

Mullane, N., Healy, B., Meade, J., Whyte, P., Wall, P. G., \& Fanning, S. (2008). Dissemination of Cronobacter spp. (Enterobacter sakazakii) in a powdered milk protein manufacturing facility. Appl Environ Microbiol, 74(19), 59135917.

Muller, A., Rychli, K., Muhterem-Uyar, M., Zaiser, A., Stessl, B., Guinane, C. M., et al. (2013). Tn6188-a novel transposon in Listeria monocytogenes responsible for tolerance to benzalkonium chloride. PLoS One, 8(10), e76835.

Murphy, C., Carroll, C., \& Jordan, K. N. (2006). Environmental survival mechanisms of the foodborne pathogen Campylobacter jejuni. Journal of Applied Microbiology, 100(4), 623-632.

Nart, P., Holden, N., McAteer, S. P., Wang, D., Flockhart, A. F., Naylor, S. W., et al. (2008). Mucosal antibody responses of colonized cattle to Escherichia coli 0157secreted proteins, flagellin, outer membrane proteins and lipopolysaccharide. FEMS Immunology and Medical Microbiology, 52(1), 59-68.

Nataro, J. P., \& Kaper, J. B. (1998). Diarrheagenic Escherichia coli. Clinical Microbiology Reviews, 11(1), 142-201.

Naylor, S. W., Low, J. C., Besser, T. E., Mahajan, A., Gunn, G. J., Pearce, M. C., et al. (2003). Lymphoid follicle-dense mucosa at the terminal rectum is the principal site of colonization of enterohemorrhagic Escherichia coli 0157:H7 in the bovine host. Infection and Immunity, 71(3), 1505-1512.

Naylor, S. W., Roe, A. J., Nart, P., Spears, K., Smith, D. G. E., Low, J. C., et al. (2005). Escherichia coli 0157:H7 forms attaching and effacing lesions at the terminal rectum of cattle and colonization requires the LEE4 operon. Microbiology-SGM, 151, 2773-2781.

Nazarowec-White, M., \& Farber, J. M. (1999). Phenotypic and genotypic typing of food and clinical isolates of Enterobacter sakazakii. Journal of Medical Microbiology, 48(6), 559-567.

Nesbakken, T., Kapperud, G., \& Caugant, D. A. (1996). Pathways of Listeria monocytogenes contamination in the meat processing industry. International Journal of Food Microbiology, 31(1-3), 161-171.

Nesse, L. L., Nordby, K., Heir, E., Bergsjoe, B., Vardund, T., Nygaard, H., et al. (2003). Molecular analyses of Salmonella enterica isolates from fish feed factories and fish feed ingredients. Applied and Environmental Microbiology, 69(2), 1075-1081.

Nesse, L. L., Refsum, T., Heir, E., Nordby, K., Vardund, T., \& Holstad, G. (2005). Molecular epidemiology of Salmonella spp. isolates from gulls, fish-meal factories, feed factories, animals and humans in Norway based on pulsed-field gel electrophoresis. Epidemiology and Infection, 133(1), 53-58.

Newell, D. G., Elvers, K. T., Dopfer, D. Hansson, I., Jones, P., James, S., et al. (2011). Biosecurity-based interventions and strategies to reduce Campylobacter spp. on poultry farms. Applied and Environmental Microbiology, 77(24), 8605-8614.

Nielsen, L. R. (2013). Review of pathogenesis and diagnostic methods of immediate relevance for epidemiology and control of Salmonella Dublin in cattle. Veterinary Microbiology, 162(1), 1-9.

Norberg, S., Stanton, C., Ross, R. P., Hill, C., Fitzgerald, G. F., \& Cotter, P. D. (2012). Cronobacter spp. in powdered infant formula. Journal of Food Protection, 75(3), $607-620$.

Norwood, D. E., \& Gilmour, A. (1999). Adherence of Listeria monocytogenes strains to stainless steel coupons. Journal of Applied Microbiology, 86(4), 576-582.

Norwood, D. E., \& Gilmour, A. (2000). The growth and resistance to sodium hypochlorite of Listeria monocytogenes in a steady-state multispecies biofilm. Journal of Applied Microbiology, 88(3), 512-520.

O'Brien, S. J., Adak, G. K., \& Gilham, C. (2001). Contact with farming environment as a major risk factor for shiga toxin (verocytotoxin)-producing Escherichia coli 0157 infection in humans. Emerging Infectious Diseases, 7(6), 1049-1051.

Ogden, I. D., Hepburn, N. F., MacRae, M., Strachan, N. J. C., Fenlon, D. R., Rusbridge, S. M., et al. (2002). Long-term survival of Escherichia coli 0157 on pasture following an outbreak associated with sheep at a scout camp. Letters in Applied Microbiology, 34(2), 100-104.

Ojeniyi, B., Christensen, J., \& Bisgaard, M. (2000). Comparative investigations of Listeria monocytogenes isolated from a turkey processing plant, turkey products, and from human cases of listeriosis in Denmark. Epidemiology and Infection, 125(2), 303-308.

Ojeniyi, B., Wegener, H. C., Jensen, N. E., \& Bisgaard, M. (1996). Listeria monocytogenes in poultry and poultry products: epidemiological investigations in seven Danish abattoirs. Journal of Applied Bacteriology, 80(4), 395-401.

Orquera, S., Golz, G., Sparborth, D., Joldic, A., \& Alter, T. (2012). Are marinades capable of reducing Campylobacter cell counts in chicken meat? Fleischwirtschaft, 92(8), 95-98.

Orsi, R. H., Borowsky, M. L., Lauer, P., Young, S. K., Nusbaum, C., Galagan, J. E., et al. (2008). Short-term genome evolution of Listeria monocytogenes in a noncontrolled environment. BMC Genomics, 9(539), 1471-2164.

Osaili, T., \& Forsythe, S. (2009). Desiccation resistance and persistence of Cronobacter species in infant formula. International Journal of Food Microbiology, 136(2), 214-220. 
Osterberg, J., Vagsholm, I., Boqvist, S., \& Lewerin, S. S. (2006). Feed-borne outbreak of Salmonella Cubana in Swedish pig farms: risk factors and factors affecting the restriction period in infected farms. Acta Veterinaria Scandinavica, 47(1), 13-21.

Pan, Y., Breidt, F., Jr., \& Kathariou, S. (2006). Resistance of Listeria monocytogenes biofilms to sanitizing agents in a simulated food processing environment. Applied and Environmental Microbiology, 72(12), 7711-7717.

Pan, Y., Breidt, F., Jr., \& Kathariou, S. (2009). Competition of Listeria monocytogenes serotype $1 / 2 \mathrm{a}$ and $4 \mathrm{~b}$ strains in mixed-culture biofilms. Applied and Environmental Microbiology, 75(18), 5846-5852.

Papenbrock, S., Stemme, K., Amtsberg, G., Verspohl, J., \& Kamphues, J. (2005). Investigations on prophylactic effects of coarse feed structure and/or potassium diformate on the microflora in the digestive tract of weaned piglets experimentally infected with Salmonella Derby. Journal of Animal Physiology and Animal Nutrition, 89(3-6), 84-87.

Perez-Boto, D., Garcia-Pena, F. J., Abad-Moreno, J. C., Hurtado-Pizarro, M. D., PerezCobo, I., \& Aurora Echeita, M. (2010). Drinking water as the source of Campylobacter coli infection in grandparent heavy breeders. Avian Pathology, 39(6), 483-487.

Perko-Makela, P., Hakkinen, M., Honkanen-Buzalski, T., \& Hanninen, M. L. (2002). Prevalence of campylobacters in chicken flocks during the summer of 1999 in Finland. Epidemiology and Infection, 129(1), 187-192.

Perko-Makela, P., Isohanni, P., Katzav, M., Lund, M., Hanninen, M. L., \& Lyhs, U. (2009). A longitudinal study of Campylobacter distribution in a turkey production chain. Acta Veterinaria Scandinavica, 51.

Petersen, L., \& Wedderkopp, A. (2001). Evidence that certain clones of Campylobacter jejuni persist during successive broiler flock rotations. Applied and Environmental Microbiology, 67(6), 2739-2745.

Peyrat, M. B., Soumet, C., Maris, P., \& Sanders, P. (2008). Recovery of Campylobacter jejuni from surfaces of poultry slaughterhouses after cleaning and disinfection procedures: analysis of a potential source of carcass contamination. International Journal of Food Microbiology, 124(2), 188-194.

Poljak, Z., Dewey, C. E., Friendship, R. M., Martin, S. W., \& Christensen, J. (2008). Multilevel analysis of risk factors for Salmonella shedding in Ontario finishing pigs. Epidemiology and Infection, 136(10), 1388-1400.

Potter, A. A., Klashinsky, S., Li, Y. L., Frey, E., Townsend, H., Rogan, D., et al. (2004). Decreased shedding of Escherichia coli 0157:H7 by cattle following vaccination with type III secreted proteins. Vaccine, 22(3-4), 362-369.

Pricope, L., Nicolau, A., Wagner, M., \& Rychli, K. (2013). The effect of sublethal concentrations of benzalkonium chloride on invasiveness and intracellular proliferation of Listeria monocytogenes. Food Control, 31(1), 230-235.

Proudy, I., Bougle, D., Coton, E., Coton, M., Leclercq, R., \& Vergnaud, M. (2008a). Genotypic characterization of Enterobacter sakazakii isolates by PFGE, BOXPCR and sequencing of the fliC gene. Journal of Applied Microbiology, 104(1), 26-34.

Proudy, I., Bougle, D., Leclercq, R., \& Vergnaud, M. (2008b). Tracing of Enterobacter sakazakii isolates in infant milk formula processing by BOX-PCR genotyping. Journal of Applied Microbiology, 105(2), 550-558.

Quintana-Hayashi, M. P., \& Thakur, S. (2012). Longitudinal study of the persistence of antimicrobial-resistant Campylobacter strains in distinct swine production systems on farms, at slaughter, and in the environment. Applied and Environmental Microbiology, 78(8), 2698-2705.

Rankin, J. D., \& Taylor, R. J. (1969). A study of some disease hazards which could be associated with the system of applying cattle slurry to pasture. Veterinary Record, 85(21), 578-581.

Ray, B., Jezeski, J. J., \& Busta, F. F. (1971). Isolation of salmonellae from naturally contaminated dried milk products. 2-Influence of storage time on isolation of salmonellae. Journal of Milk and Food Technology, 34(9), 423.

Raya, R. R., Oot, R. A., Moore-Maley, B., Wieland, S., Callaway, T. R., Kutter, E. M., et al. (2011). Naturally resident and exogenously applied T4-like and T5-like bacteriophages can reduce Escherichia coli 0157:H7 levels in sheep guts. Bacteriophage, 1(1), 15-24.

Rayman, M. K., D’Aoust, J. Y., Aris, B., Maishment, C., \& Wasik, R. (1979). Survival of microorganisms in stored pasta. Journal of Food Protection, 42(4), 330-334.

Reij, M. W., Den Aantrekker, E. D., \& ILSI Europe Risk Analysis in Microbiology Task Force. (2004). Recontamination as a source of pathogens in processed foods. International Journal of Food Microbiology, 91(1), 1-11.

Riedel, K., \& Lehner, A. (2007). Identification of proteins involved in osmotic stress response in Enterobacter sakazakii by proteomics. Proteomics, 7(8), 1217-1231.

Rivas, L., Coffey, B., McAuliffe, O., McDonnell, M. J., Burgess, C. M., Coffey, A., et al. (2010). In vivo and ex vivo evaluations of bacteriophages e $11 / 2$ and e $4 / 1 \mathrm{c}$ for use in the control of Escherichia coli 0157:H7. Applied and Environmental Microbiology, 76(21), 7210-7216.

Rodrigues, D., Teixeira, P., Oliveira, R., \& Azeredo, J. (2011). Salmonella enterica Enteritidis biofilm formation and viability on regular and triclosanimpregnated bench cover materials. Journal of Food Protection, 74(1), 32-37.

Rodriguez, A., \& McLandsborough, L. A. (2007). Evaluation of the transfer of Listeria monocytogenes from stainless steel and high-density polyethylene to Bologna and American cheese. Journal of Food Protection, 70(3), 600-606.

Ronner, A. B., \& Wong, A. C. L. (1993). Biofilm development and sanitizer inactivation of Listeria monocytogenes and Salmonella Typhimurium on stainless steeel and Buna-N rubber. Journal of Food Protection, 56(9), 750-758.

Rorvik, L. M., Caugant, D. A., \& Yndestad, M. (1995). Contamination pattern of Listeria monocytogenes and other Listeria spp. in a salmon slaughterhouse and smoked salmon processing plant. International Journal of Food Microbiology, 25(1), 19-27.

Roselli, M., Finamore, A., Britti, M. S., Bosi, P., Oswald, I., \& Mengheri, E. (2005) Alternatives to in-feed antibiotics in pigs: evaluation of probiotics, zinc or organic acids as protective agents for the intestinal mucosa. A comparison of in vitro and in vivo results. Animal Research, 54(3), 203-218.

Rosenquist, H., Nielsen, N. L., Sommer, H. M., Norrung, B., \& Christensen, B. B. (2003). Quantitative risk assessment of human campylobacteriosis associated with thermophilic Campylobacter species in chickens. International Journal of Food Microbiology, 83(1), 87-103.

Sanders, S. Q., Boothe, D. H., Frank, J. F., \& Arnold, J. W. (2007). Culture and detection of Campylobacter jejuni within mixed microbial populations of biofilms on stainless steel. Journal of Food Protection, 70(6), 1379-1385.

Sasahara, K. C., \& Zottola, E. A. (1993). Biofilm formation by Listeria monocytogenes utilizes a primary colonizing microorganism in flowing systems. Journal of Food Protection, 56(12), 1022-1028.

Scott, A. E., Timms, A. R., Connerton, P. L., Loc Carrillo, C., Adzfa Radzum, K., \& Connerton, I. F. (2007). Genome dynamics of Campylobacter jejuni in response to bacteriophage predation. PLoS Pathogens, 3(8), e119.

Sheng, H. Q., Knecht, H. J., Kudva, I. T., \& Hovde, C. J. (2006). Application of bacteriophages to control intestinal Escherichia coli 0157:H7 levels in ruminants. Applied and Environmental Microbiology, 72(8), 5359-5366.

Shin, H., Lee, J. H., Choi, Y., \& Ryu, S. (2012a). Complete genome sequence of the opportunistic food-borne pathogen Cronobacter sakazakii ES15. Journal of Bacteriology, 194(16), 4438-4439.

Shin, H., Lee, J. H., Kim, Y., \& Ryu, S. (2012b). Complete genome sequence of Cronobacter sakazakii bacteriophage CR3. Journal of Virology, 86(11), 6367-6368.

Si, W., Gong, J., Tsao, R., Zhou, T., Yu, H., Poppe, C., et al. (2006). Antimicrobial activity of essential oils and structurally related synthetic food additives towards selected pathogenic and beneficial gut bacteria. Journal of Applied Microbiology, 100(2), 296-305.

Sinton, L. W., Braithwaite, R. R., Hall, C. H., \& Mackenzie, M. L. (2007). Survival of indicator and pathogenic bacteria in bovine feces on pasture. Applied and Environmental Microbiology, 73(24), 7917-7925.

Siringan, P., Connerton, P. L., Payne, R. J., \& Connerton, I. F. (2011). Bacteriophagemediated dispersal of Campylobacter jejuni biofilms. Applied and Environmenta Microbiology, 77(10), 3320-3326.

Skanseng, B., Kaldhusdal, M., Moen, B., Gjevre, A. G., Johannessen, G. S., Sekelja, M., et al. (2010). Prevention of intestinal Campylobacter jejuni colonization in broilers by combinations of in-feed organic acids. Journal of Applied Microbiology, 109(4), 1265-1273.

Skovager, A., Whitehead, K., Wickens, D., Verran, J., Ingmer, H., \& Arneborg, N. (2013). A comparative study of fine polished stainless steel, TiN and TiN/Ag surfaces: adhesion and attachment strength of Listeria monocytogenes as well as anti-listerial effect. Colloids and Surfaces B: Biointerfaces, 109, 190196.

Smole Možina, S., Klančnik, A., \& Raspor, P. (2013). Mechanisms of microbial resistance in biofilms. In M. Simoes, \& F. Mergulhão (Eds.), Biofilms in Bioengineering (pp. 311-332). Nova Science Publishers.

Smole Možina, S., Kurinčič, M., Klančnik, A., \& Mavri, A. (2011). Campylobacter and its multi-resistance in the food chain. Trends in Food Science \& Technology, 22(23), 91-98.

Snelling, W. J., McKenna, J. P., Lecky, D. M., \& Dooley, J. S. G. (2005). Survival of Campylobacter jejuni in waterborne protozoa. Applied and Environmental Microbiology, 71(9), 5560-5571.

Soerjadi, A. S., Snoeyenbos, G. H., \& Weinack, O. M. (1982). Intestinal colonization and competitive exclusion of Campylobacter fetus subsp. jejuni in young chicks. Avian Diseases, 26(3), 520-524.

Solis de Los Santos, F., Donoghue, A. M., Venkitanarayanan, K., Dirain, M. L., ReyesHerrera, I., Blore, P. J., et al. (2008). Caprylic acid supplemented in feed reduces enteric Campylobacter jejuni colonization in ten-day-old broiler chickens. Poultry Science, 87(4), 800-804.

Somers, E. B., \& Wong, A. C. L. (2004). Efficacy of two cleaning and sanitizing combinations on Listeria monocytogenes biofilms formed at low temperature on a variety of materials in the presence of ready-to-eat meat residue. Journal of Food Protection, 67(10), 2218-2229.

Stanga, M. (2010). Biofilm. In Sanitation (pp. 441-457). Wiley-VCH Verlag GmbH \& Co. KGaA.

Stephan, R., Lehner, A., Tischler, P., \& Rattei, T. (2011). Complete genome sequence of Cronobacter turicensis LMG 23827, a food-borne pathogen causing deaths in neonates. Journal of Bacteriology, 193(1), 309-310.

Stephens, T. P., Loneragan, G. H., Chichester, L. M., \& Brashears, M. M. (2007) Prevalence and enumeration of Escherichia coli 0157 in steers receiving various strains of Lactobacillus-based direct-fed microbials. Journal of Food Protection, 70(5), 1252-1255.

Stern, N. J., Bailey, J. S., Blankenship, L. C., Cox, N. A., \& McHan, F. (1988). Colonization characteristics of Campylobacter jejuni in chick ceca. Avian Diseases, 32(2), 330334.

Stern, N. J., Cox, N. A., Musgrove, M. T., \& Park, C. M. (2001). Incidence and levels of Campylobacter in broilers after exposure to an inoculated seeder bird. Journal of Applied Poultry Research, 10(4), 315-318.

Stessl, B., Fricker, M., Fox, E., Karpiskova, R., Demnerova, K., Jordan, K., et al. (2014). Collaborative survey on the colonization of different types of cheese-processing facilities with Listeria monocytogenes. Foodborne Pathogens and Disease, 11(1), 8-14. 
Swaggerty, C. L., Pevzner, I. Y., He, H. Q., Genovese, K. J., Nisbet, D. J., Kaiser, P., et al. 2009). Selection of broilers with improved innate immune responsiveness to reduce on-farm infection by foodborne pathogens. Foodborne Pathogens and Disease, 6(7), 777-783.

Swyers, K. L., Carlson, B. A., Nightingale, K. K., Belk, K. E., \& Archibeque, S. L. (2011). Naturally colonized beef cattle populations fed combinations of yeast culture and an ionophore in finishing diets containing dried distiller's grains with solubles had similar fecal shedding of Escherichia coli 0157:H7. Journal of Food Protection, 74(6), 912-918.

Tannock, G. W., \& Smith, J. M. B. (1971). Studies on the survival of Salmonella Typhimurium and Salmonella Bovismorbificans on pasture and in water. Australian Veterinary Journal, 47(11), 557-559.

Teh, K. H., Flint, S., \& French, N. (2010). Biofilm formation by Campylobacter jejuni in controlled mixed-microbial populations. International Journal of Food Microbiology, 143(3), 118-124.

Thomas, K. M., McCann, M. S., Collery, M. M., Logan, A., Whyte, P., McDowell, D. A et al. (2012). Tracking verocytotoxigenic Escherichia coli 0157, 026, 0111, 0103 and 0145 in Irish cattle. International Journal of Food Microbiology, 153(3), 288296.

Thunegard, E. (1975). On the persistence of bacteria in manure. A field and experimental study with special reference to Salmonella in liquid manure. Acta Veterinaria Scandinavica, 56(Supplement), 5-86.

Tompkin, B. A. (2002). Control of Listeria in the food-processing environment Journal of Food Protection, 65(4), 709-723.

Unnerstad, H., Bannerman, E., Bille, J., DanielssonTham, M. L., Waak, E., \& Tham, W. (1996). Prolonged contamination of a dairy with Listeria monocytogenes Netherlands Milk and Dairy Journal, 50(4), 493-499.

van Acker, J., de Smet, F., Muyldermans, G., Bougatef, A., Naessens, A., \& Lauwers, S. (2001). Outbreak of necrotizing enterocolitis associated with Enterobacter sakazakii in powdered milk formula. Journal of Clinical Microbiology, 39(1), 293297.

Van der Veen, S., \& Abee, T. (2011). Mixed species biofilms of Listeria monocytogenes and Lactobacillus plantarum show enhanced resistance to benzalkonium chloride and peracetic acid. International Journal of Food Microbiology, 144(3), 421431.

Van der Wolf, P. J., Bongers, J. H., Elbers, A. R. W., Franssen, F., Hunneman, W. A., van Exsel, A. C. A., et al. (1999). Salmonella infections in finishing pigs in The Netherlands: bacteriological herd pre-valence, serogroup and antibiotic resistance of isolates and risk factors for infection. Veterinary Microbiology, 67(4), $263-275$.

Van der Wolf, P. J., Wolbers, W. B., Elbers, A. R. W., van der Heijden, H., Koppen, J. Hunneman, W. A., et al. (2001). Herd level husbandry factors associated with the serological Salmonella prevalence in finishing pig herds in The Netherlands. Veterinary Microbiology, 78(3), 205-219.

Van Deun, K., Haesebrouck, F., Van Immerseel, F., Ducatelle, R., \& Pasmans, F. (2008). Short-chain fatty acids and L-lactate as feed additives to control Campylobacter jejuni infections in broilers. Avian Pathology, 37(4), 379-383.

Van Donkersgoed, J., Hancock, D., Rogan, D., \& Potter, A. A. (2005). Escherichia coli 0157:H7 vaccine field trial in 9 feedlots in Alberta and Saskatchewan. Canadian Veterinary Journal, 46(8), 724-728.

Van Gerwe, T., Bouma, A., Klinkenberg, D., Wagenaar, J. A., Jacobs-Reitsma, W. F., \& Stegeman, A. (2010). Medium chain fatty acid feed supplementation reduces the probability of Campylobacter jejuni colonization in broilers. Veterinary Microbiology, 143(2-4), 314-318.

Van Winsen, R. L., Keuzenkamp, D., Urlings, B. A. P. Lipman, L. J. A. Snijders, J. A. M., Verheijden, J. H. M., et al. (2002). Effect of fermented feed on shedding of Enterobacteriaceae by fattening pigs. Veterinary Microbiology, 87(3), 267-276.

Vatanyoopaisarn, S., Nazli, A., Dodd, C. E. R., Rees, C. E. D., \& Waites, W. M. (2000) Effect of flagella on initial attachment of Listeria monocytogenes to stainless steel. Applied and Environmental Microbiology, 66(2), 860-863.

Verghese, B., Lok, M., Wen, J., Alessandria, V., Chen, Y., Kathariou, S., et al. (2011) comK prophage junction fragments as markers for Listeria monocytogenes genotypes unique to individual meat and poultry processing plants and a model for rapid niche-specific adaptation, biofilm formation, and persistence. Applied and Environmental Microbiology, 77(10), 3279-3292.
Vestby, L. K., Moretro, T., Langsrud, S., Heir, E., \& Nesse, L. L. (2009). Biofilm forming abilities of Salmonella are correlated with persistence in fish meal and feed factories. BMC Veterinary Research, 5.

Vogel, B. F., Hansen, L. T., Mordhorst, H., \& Gram, L. (2010). The survival of Listeria monocytogenes during long term desiccation is facilitated by sodium chloride and organic material. International Journal of Food Microbiology, 140(2-3), 192-200.

Vogel, B. F., Huss, H. H., Ojeniyi, B., Ahrens, P., \& Gram, L. (2001). Elucidation of Listeria monocytogenes contamination routes in cold-smoked salmon processing plants detected by DNA-based typing methods. Applied and Environmental Microbiology, 67(6), 2586-2595.

Von Altrock, A., Schutte, A., \& Hildebrandt, G. (2000). Results of the German investigation in the EU-project "Salmonella in Pork (Salinpork)" - part 1: investigations in the farms. Berliner und Munchener Tierarztliche Wochenschrift, 113(5), 191-201.

Vongkamjan, K., Roof, S., Stasiewicz, M. J., \& Wiedmann, M. (2013). Persistent Listeria monocytogenes subtypes isolated from a smoked fish processing facility included both phage susceptible and resistant isolates. Food Microbiology, 35(1), $38-48$.

Wagenaar, J. A., Van Bergen, M. A., Mueller, M. A., Wassenaar, T. M., \& Carlton, R. M. (2005). Phage therapy reduces Campylobacter jejuni colonization in broilers. Veterinary Microbiology, 109(3-4), 275-283.

Wales, A. D., Allen, V. M., \& Davies, R. H. (2010). Chemical treatment of animal feed and water for the control of Salmonella. Foodborne Pathogens and Disease, 7(1), 3-15.

Wall, S. K., Zhang, J., Rostagno, M. H., \& Ebner, P. D. (2010). Phage therapy to reduce preprocessing Salmonella infections in market-weight swine. Applied and Environmental Microbiology, 76(1), 48-53.

Wallace, R. J. (2004). Antimicrobial properties of plant secondary metabolites. Proceedings of the Nutrition Society, 63(04), 621-629.

Walsh, D., Molloy, C., Iversen, C., Carroll, J., Cagney, C., Fanning, S., et al. (2011). Survival characteristics of environmental and clinically derived strains of Cronobacter sakazakii in infant milk formula (IMF) and ingredients. Journal of Applied Microbiology, 110(3), 697-703.

Warnick, L. D., Crofton, L. M., Pelzer, K. D., \& Hawkins, M. J. (2001). Risk factors for clinical salmonellosis in Virginia, USA cattle herds. Preventive Veterinary Medicine, 49(3-4), 259-275.

Wells, J. E., Yen, J. T., \& Miller, D. N. (2005). Impact of dried skim milk in production diets on Lactobacillus and pathogenic bacterial shedding in growing-finishing swine. Journal of Applied Microbiology, 99(2), 400-407.

Wierup, M., \& Haggblom, P. (2010). An assessment of soybeans and other vegetable proteins as source of Salmonella contamination in pig production. Acta Veterinaria Scandinavica, 52, 15.

Williams, J. E., \& Benson, S. T. (1978). Survival of Salmonella Typhimurium in poultry feed and litter at 3 temperatures. Avian Diseases, 22(4), 742-747.

Wirz, S. E., Overesch, G., Kuhnert, P., \& Korczak, B. M. (2010). Genotype and antibiotic resistance analyses of Campylobacter isolates from ceca and carcasses of slaughtered broiler flocks. Applied and Environmental Microbiology, 76(19), 6377-6386.

Wulff, G., Gram, L., Ahrens, P., \& Vogel, B. F. (2006). One group of genetically similar Listeria monocytogenes strains frequently dominates and persists in several fish slaughter- and smokehouses. Applied and Environmental Microbiology, 72(6), 4313-4322.

Yan, Q., Condell, O., Power, K., Butler, F., Tall, B. D., \& Fanning, S. (2012). Cronobacter species (formerly known as Enterobacter sakazakii) in powdered infant formula: a review of our current understanding of the biology of this bacterium. Journal of Applied Microbiology, 113(1), 1-15.

Yan, Q., Power, K. A., Cooney, S., Fox, E., Gopinath, G. R., Grim, C. J., et al. (2013). Complete genome sequence and phenotype microarray analysis of Cronobacter sakazakii SP291: a persistent isolate cultured from a powdered infant formula production facility. Frontiers in Microbiology, 4, 256.

Zhang, Q. J., Sahin, O., McDermott, P. F., \& Payot, S. (2006). Fitness of antimicrobialresistant Campylobacter and Salmonella. Microbes and Infection, 8(7), 1972-1978.

Zorman, T., Heyndrickx, M., Uzunovic-Kamberovic, S., \& Mozina, S. S. (2006) Genotyping of Campylobacter coli and C. jejuni from retail chicken meat and humans with campylobacteriosis in Slovenia and Bosnia and Herzegovina. International Journal of Food Microbiology, 110(1), 24-33. 